\title{
Article
}

\section{Organotrialkoxysilane-Functionalized Prussian Blue Nanoparticles-Mediated Fluorescence Sensing of Arsenic(III)}

\author{
Prem. C. Pandey ${ }^{1}\left(\mathbb{D}\right.$, Shubhangi Shukla ${ }^{1}\left(\mathbb{D}\right.$ and Roger J. Narayan ${ }^{2, *}(\mathbb{D}$ \\ 1 Department of Chemistry, Indian Institute of Technology (BHU), Varanasi 221005, India; \\ pcpandey.apc@iitbhu.ac.in (P.C.P.); shubhangi.rs.chy14@itbhu.ac.in (S.S.) \\ 2 Joint Department of Biomedical Engineering, University of North Carolina, Chapel Hill, NC 27599, USA \\ * Correspondence: rjnaraya@ncsu.edu
}

Citation: Pandey, P..C.; Shukla, S.; Narayan, R.J. OrganotrialkoxysilaneFunctionalized Prussian Blue Nanoparticles-Mediated Fluorescence Sensing of Arsenic(III). Nanomaterials 2021, 11, 1145. https://doi.org/ 10.3390/nano11051145

Academic Editors: Henry Radamson, Guilei Wang and Antonios Kelarakis

Received: 16 February 2021

Accepted: 26 April 2021

Published: 28 April 2021

Publisher's Note: MDPI stays neutral with regard to jurisdictional claims in published maps and institutional affiliations.

\begin{abstract}
Prussian blue nanoparticles (PBN) exhibit selective fluorescence quenching behavior with heavy metal ions; in addition, they possess characteristic oxidant properties both for liquid-liquid and liquid-solid interface catalysis. Here, we propose to study the detection and efficient removal of toxic arsenic(III) species by materializing these dual functions of PBN. A sophisticated PBN-sensitized fluorometric switching system for dosage-dependent detection of $\mathrm{As}^{3+}$ along with PBN-integrated $\mathrm{SiO}_{2}$ platforms as a column adsorbent for biphasic oxidation and elimination of $\mathrm{As}^{3+}$ have been developed. Colloidal PBN were obtained by a facile two-step process involving chemical reduction in the presence of 2-(3,4-epoxycyclohexyl)ethyl trimethoxysilane (EETMSi) and cyclohexanone as reducing agents, while heterogeneous systems were formulated via EETMSi, which triggered in situ growth of PBN inside the three-dimensional framework of silica gel and silica nanoparticles $\left(\mathrm{SiO}_{2}\right)$. PBN-induced quenching of the emission signal was recorded with an $\mathrm{As}^{3+}$ concentration (0.05-1.6 ppm)-dependent fluorometric titration system, owing to the potential excitation window of PBN (at 480-500 nm), which ultimately restricts the radiative energy transfer. The detection limit for this arrangement is estimated around $0.025 \mathrm{ppm}$. Furthermore, the mesoporous and macroporous PBN-integrated $\mathrm{SiO}_{2}$ arrangements might act as stationary phase in chromatographic studies to significantly remove $\mathrm{As}^{3+}$. Besides physisorption, significant electron exchange between $\mathrm{Fe}^{3+} / \mathrm{Fe}^{2+}$ lattice points and $\mathrm{As}^{3+}$ ions enable complete conversion to less toxic $\mathrm{As}^{5+}$ ions with the repeated influx of mobile phase. $\mathrm{PBN}$-integrated $\mathrm{SiO}_{2}$ matrices were successfully restored after segregating the target ions. This study indicates that $\mathrm{PBN}$ and $\mathrm{PBN}$-integrated $\mathrm{SiO}_{2}$ platforms may enable straightforward and low-cost removal of arsenic from contaminated water.
\end{abstract}

Keywords: prussian blue nanoparticles; organotrialkoxysilane; silica beads; arsenite; arsenate; water decontamination

\section{Introduction}

Large numbers of people in Bangladesh and India are exposed to arsenic contamination in potable water. Metallurgical, agricultural, and industrial processes result in the discharge of arsenic into soil and water [1,2]. Long-term exposure to arsenic, even at low concentrations, can lead to oncological, immunological, neurological, and endocrine effects [3]. The World Health Organization recently set an arsenic limit of $10 \mu \mathrm{g} / \mathrm{L}$ for drinking water (Holm, 2002) [4]. Natural water predominantly contains the inorganic species arsenate $\left[\mathrm{HAsO}_{4}{ }^{2-}, \mathrm{As}(\mathrm{V})\right]$ and arsenite $\left[\mathrm{AsO}_{2}{ }^{-}, \mathrm{As}(\mathrm{III})\right]$. Inorganic $\mathrm{As}(\mathrm{III})$ was noted to be more toxic (10 times), mobile, and water-soluble (4-10 times) than As(V) [5]. The conversion rate of As(III) (arsenite) to As(V) (arsenate) in oxygenated water is a slow process, which depends on certain specific conditions [6]. Consequently, there is an alarming need to develop novel methods for sensing and removal of arsenic from drinking water [7].

Prussian blue nanoparticles (PBN) contain metal in two different oxidation states, $\mathrm{Fe}^{+3}$ and $\mathrm{Fe}^{+2}$; these materials are known for their advanced peroxidase mimetic activity [8-10]. 
The charge transfer between the two iron species is responsible for the deep blue color of the complex [11]. Bi-metallic coordination compound PBN are a well-known inorganic material for electrocatalytic applications [12-15]. Several reports demonstrated the formation of mixed metal analogues, which involve straightforward replacement of the ferric/ferrous ion with another metal having a similar chemical state [16-18]. The properties of Prussian blue complex can be readily modified depending upon the nature of the constituent metal pair. Iron hexacyanoferrate synthesized via traditional synthetic routes (e.g., coprecipitation and electrosynthesis) do not exhibit appropriate processability for technical applications. We processed PBN from a single precursor involving the active role of the organotrialkoxysilane, which not only controlled the nucleation and solubility but also provided stability to the contents of reaction medium [19]. In addition, the PBN made from a single precursor were found to act as a light quenching material [20]; the photoactivity of the materials was examined using fluorescence imaging. Earlier studies show that organotrialkoxysilanes such as 3-aminopropyltrimethoxysilane (APTMS) allow the conversion of a single precursor, potassium hexacyanoferrate, to Prussian blue; this material was used for electrocatalytic detection of dopamine [21]. We further examined the use of another organotrialkoxysilane, 2-(3,4-epoxycyclohexyl) ethyltrimethoxysilane (EETMSi), in the presence of cyclohexanone for the controlled synthesis of PBN as a light quenching material.

Several methods, including iron oxide-coated sand, manganese greens, and iron ores, were previously described for arsenic removal [22]. Spectrophotometric and fluorometric methods have been previously studied to estimate the trace amounts of arsenite in water [23-25]. PBN, which include iron of two different oxidation states in a metal framework, may undergo specific interactions with As(III). Thus, we examined the fluorescence quenching ability of the PBN in the presence of arsenic(III). A novel result based on fluorescent sensing of arsenic was recorded, indicating the interaction between PBN and arsenic(III). PBN within a matrix were subsequently studied for use in arsenic removal.

Silica $\left(\mathrm{SiO}_{2}\right)$ beads are a non-toxic and inexpensive matrix, which may be used as a template to synthesize PBN using organotrialkoxysilane. PBN were inserted into mesoporous $\mathrm{SiO}_{2}$; the PBN became embedded in the accessible $\mathrm{SiO}_{2}$ pores. The $\mathrm{PBN} @ \mathrm{SiO}_{2}$ was used for As(III) removal and its subsequent oxidation into arsenate through an interaction with the iron species in the material. This adsorption-oxidation process was demonstrated with $\mathrm{PBN} @ S i O_{2}$ under different $\mathrm{pH}$ conditions to analyze the efficacy of the oxidant system. The high uptake efficiency of $\mathrm{PBN} @ \mathrm{SiO}_{2}(95 \%)$ indicated that this material is attractive for use in As(III) removal. XPS, ICP, and HPLC techniques were used to detect and quantify As(III) species. The PBN@SiO 2 was separated easily through centrifugation; this recycled material also showed As(III) removal activity. The proposed As(III) removal process is more cost effective over those reported to date. The ability to recycle $\mathrm{PBN} @ \mathrm{SiO}_{2}$ adds to the economic viability of this process.

\section{Experimental Section}

\subsection{Materials}

Potassium ferricyanide was purchased from Merck India (Bengaluru, Karnataka, India). Silica beads $(50 \mu \mathrm{m})$ and silica nanoparticles $(200 \mathrm{~nm})$ were purchased from SigmaAldrich (Bengaluru, Karnataka, India). Sodium arsenite was purchased from S D Fine-chem Limited (Mumbai, Maharashtra, India), and Azure-B was obtained from Sisco Research Laboratories Pvt. Ltd. (Mumbai, Maharashtra, India). 2-(3,4-epoxycyclohexyl)ethyltrimethoxysilane (EETMSi) and cyclohexanone were obtained from Sigma-Aldrich (Bengaluru, Karnataka, India). In addition, the remaining chemicals were of analytical grade and procured from commercial sources. The working solution of As(III) was freshly prepared with Milli-Q water using sodium arsenite $\left(\mathrm{NaAsO}_{2}\right)$ and stored in a dark freezer. Milli-Q water was used throughout the experiment to avoid interference from contaminants. 


\subsection{Synthesis of PBN, PBN@SiO $\mathrm{S}_{2}$ and PBN@MSNP Mediated through EETMSi}

\subsubsection{EETMSi-Mediated Formation of PBN}

The synthesis of PBN was accomplished using [2-(3,4-Epoxycyclohexyl)ethyl]trimethoxysilane(EETMSi) and cyclohexanone from the single precursor potassium ferricyanide via chemical reduction. The homogeneous colloidal sol of Prussian blue nanoparticles (PBN) was prepared by adding $20 \mu \mathrm{L}$ of EETMSi $(0.1 \mathrm{M})$ to $100 \mu \mathrm{L}$ of potassium ferricyanide $(0.03 \mathrm{M})$ under stirring conditions. Subsequently, $20 \mu \mathrm{L}$ of cyclohexanone was added to the reaction mixture; this mixture was kept in an oven at $343 \mathrm{~K}$ for $8 \mathrm{~h}$. The blue-colored colloidal suspension of PBN was characterized byX-ray diffraction (XRD), Transmission electron micrpscopy (TEM), etc.

\subsubsection{EETMSi-Mediated Formation of Prussian Blue Nanoparticles Modified Silica (PBN@SiO ${ }_{2}$ )}

Mesoporous silica was used to obtain PBN-confined mesoporous silica $\left(\mathrm{PBN} @ S i O_{2}\right)$. Typical synthesis involved a multistep procedure as follows: At first, $10 \mathrm{mg}$ of mesoporous silica beads were suspended in $100 \mathrm{~mL}$ of EETMSi (1.2 M) aqueous solution under constant stirring conditions. After $3 \mathrm{~h}$, un-adsorbed EETMSi was extracted with methanol, followed by centrifugation. $200 \mathrm{~mL}$ of potassium ferricyanide $\left[\mathrm{K}_{3} \mathrm{Fe}(\mathrm{CN})_{6}\right]$ aqueous solution $(0.03 \mathrm{M})$ was added to the alkoxysilane-modified $\mathrm{SiO}_{2}$ suspension under vigorous stirring conditions (800 rpm). Cyclohexanone was added to the alkoxysilane-modified $\mathrm{K}_{3} \mathrm{Fe}(\mathrm{CN})_{6} @ \mathrm{SiO}_{2}$ suspension under vigorous stirring and left to stand in oven at $338 \mathrm{~K}$ overnight. The unreacted $\mathrm{K}_{3} \mathrm{Fe}(\mathrm{CN})_{6}$ and unabsorbed $\mathrm{PBN}$ were removed via washing (five times) with methanol/water (2:1) solvent. The residual material was collected after centrifugation; a drying step was subsequently performed.

\subsubsection{EETMSi-Mediated Formation of PBN@MSNPs}

Mesoporous silica nanoparticles (MSNPs) were used to prepare Prussian blue nanoparticleembedded mesoporous silica nanoparticles (PBN@MSNP). Ten milligrams of mesoporous silica nanoparticles (average particle size $200 \mathrm{~nm}$ and pore size $6 \mathrm{~nm}$ ) were suspended in $100 \mathrm{~mL}$ of EETMSi (1.2 M) aqueous solution under stirring conditions. After $3 \mathrm{~h}$, un-adsorbed EETMSi was removed with methanol, followed by centrifugation. Two hundred milliliters of potassium ferricyanide aqueous solution $(0.03 \mathrm{M})$ were added to the alkoxysilane-modified MSNP suspension under vigorous stirring conditions (800 rpm). Cyclohexanone was added to the alkoxysilane-modified $\mathrm{K}_{3} \mathrm{Fe}(\mathrm{CN})_{6} @ M S N P s$ suspension under continuous stirring and left to stand in oven at $338 \mathrm{~K}$ overnight. The unreacted $\mathrm{K}_{3} \mathrm{Fe}(\mathrm{CN})_{6}$ and unabsorbed PBN were removed via washing (five times) with methanol/water (2:1) solvent. The residual material (PBN@MSNPs) was collected after centrifugation; a drying step was subsequently performed.

\subsection{Materials Characterization}

The particle size and morphology of as-synthesized PBN/PBN@SiO ${ }_{2}$ and PBN@MSNP were analyzed using high-resolution transmission electron microscopy (HRTEM) with 800 and 8100 instruments (Hitachi, Tokyo, Japan) at an acceleration voltage of $200 \mathrm{kV}$. The topographical properties of as-synthesized $\mathrm{PBN}$ over $\mathrm{SiO}_{2}$ were analyzed using a field emission scanning electron microscopy instrument (FEI (S.E.A.) Pte Ltd., Singapore). The elemental confirmation and mapping analyses were accomplished with an EDX attachment (Oxford Instruments plc, Abingdon, UK). A Rigaku X-ray diffractometer (Rikagu, Tokyo, Japan) with $\mathrm{Cu}$ Ka radiation $\left(\lambda=1.5406 \mathrm{~A}^{0}\right)$ was used to evaluate diffraction data. The XRD analysis was performed over the scan range of $10-90^{\circ}$ for PBN. FTIR spectra were recorded on an ALFA-ATR Fourier transform infrared spectrometer (Bruker, Ettington, Germany). XPS analysis was performed using an ESCA/AES System (Surface Nano Analysis, GmbH, Berlin, Germany), which was equipped with an Al-K $\alpha(1486.6 \mathrm{eV}) \mathrm{X}$-ray source operating at a power of $385 \mathrm{~W}$ and a PHOBIOS $1503 \mathrm{D}$ energy hemispherical analyzer with a delayline detector (SPECS Surface Nano Analysis GmbH, Berlin, Germany). The C-1s peak (284.5 eV) 
was used as an internal reference to calibrate the absolute binding energy. The quantitative detection of elements was performed through ICP techniques. Fluorescence analysis was performed using a 7100 spectrophotometer (Hitachi, Tokyo, Japan). Arsenic speciation was performed using high-performance liquid chromatography (HPLC) with a Shim-packed GIST C18 chromatography column encompassing a hydrophobic (non-polar) stationary phase (column length $=75 \mathrm{~mm}$, inner diameter $=7.6 \mathrm{~mm}$ ) for the determination of all species. Ammonium phosphate solution was used as an eluent for the entire HPLC experiment. The HPLC mobile phases of ammonium phosphate solution with $\mathrm{pH} 6.9$ were prepared by mixing monobasic $\left(\mathrm{NH}_{4} \mathrm{H}_{2} \mathrm{PO}_{4}\right)$ and dibasic $\left(\left(\mathrm{NH}_{4}\right)_{2} \mathrm{HPO}_{4}\right)$ salt solutions with an appropriate ratio.

\subsection{Fluorometric Method}

A fluorometric method was used for the determination of As(III) species. Fluorescein (Flo) was used as a probe molecule $(\lambda \mathrm{ex}=480 \mathrm{~nm}, \lambda \mathrm{em}=510 \mathrm{~nm})$ for the estimation of As(III) species. The fluorescence experiment was performed under neutral $\mathrm{pH}$ (6.8) conditions using Milli-Q water. Different concentrations of As(III) standard solution (10 ppm to 320 ppm) were prepared by adding appropriate amounts of sodium arsenite to Milli-Q water. The result was obtained using the effective concentration of Flo, PBN, and As(III).

\section{Results and Discussion}

\subsection{Organotrialkoxysilane-Mediated Synthesis of PBN Analogs}

Organotrialkoxysilane with an amine functional group, APTMS, in the presence of cyclohexanone was previously used for the controlled conversion of a single precursor, $\mathrm{K}_{3}\left[\mathrm{Fe}(\mathrm{CN})_{6}\right.$, into Prussian blue nanoparticles under ambient conditions [20]. Subsequently, 2-(3,4-epoxycyclohexyl) ethyltrimethoxysilane (EETMSi) was used to make PBN in the absence of cyclohexanone [9]. Although the process enabled efficient conversion of single precursor, $\mathrm{K}_{3}\left[\mathrm{Fe}(\mathrm{CN})_{6}\right.$, into Prussian blue nanoparticles, the duration was substantially longer. Accordingly, we attempted to use cyclohexanone along with EETMSi to obtain PBN from a single precursor pathway. Indeed, the process enabled the rapid formation of PBN, as shown in Figure 1; additional details on this process are provided below.

\subsubsection{PBN as a Homogeneous Suspension}

Slow decomposition under hydrothermal conditions via single precursor synthesis readily produced a blue-colored solution of PBN. The TEM micrographs in Figure 1A,B revealed well-dispersed nanocubes of PBN with an average diameter of $30 \mathrm{~nm}$. The histogram (inset of Figure 1A) shows broad size distribution of crystalline nanoparticles, ranging between 27 and $53 \mathrm{~nm}$. The average width of nanoparticles may be altered by modifying the EETMSi $/ \mathrm{Fe}^{3+} /$ cyclohexanone feed ratio and thermal conditions. Accordingly, we investigated the role of EETMSi in combination with a ketonic reducing agent. The EDX and TEM data provided information on the chemical composition and nanoparticle structure, respectively. Figure 1D shows the contributions to the EDX spectrum from the Fe $\mathrm{K} \alpha$ peak at $6.4-7.0 \mathrm{keV}$ and $0.9 \mathrm{keV}$, the $\mathrm{Cu}$ peak at 7.8-9.0 keV, and the Si peak at $7.057 \mathrm{keV}$; Fe peak and the peaks for $\mathrm{N}, \mathrm{O}$, and $\mathrm{C}$ are also noted. The XRD spectrum shown in Figure $1 \mathrm{E}$ reveals nearly all the planes assigned to $2 \theta$ values as per JCPDS \# 73-0687, $17.4^{\circ}(200), 24.7^{\circ}(220), 35.3^{\circ}(400), 39.6^{\circ}(420)$, and $43.7^{\circ}(422), 50.0^{\circ}(440), 53.9^{\circ}(600), 57.2^{\circ}$ $(620), 66.1^{\circ}(640)$, and $68.9^{\circ}(642)$.

\subsubsection{PBN Confined in Mesoporous Silica $\left(\mathrm{PBN} @ \mathrm{SiO}_{2}\right)$}

We also attempted to insert PBN into mesoporous silica through the synergistic action of EETMSi and cyclohexanone; the product is represented as $\mathrm{PBN} @ \mathrm{SiO}_{2}$. Mesoporous silica with a particle size of 50 micrometers and a pore diameter of $6 \mathrm{~nm}$ was used for the synthetic insertion of PBN; these materials have use in column chromatography. SEM micrographs in Figure 2A-C show the topographical features of $\mathrm{PBN} @ S i O_{2}$ and the narrow size distribution of the $\mathrm{PBN}$ in the $\mathrm{SiO}_{2}$ matrix. Figure 2D shows the EDX data for 
PBN@SiO 2 , which shows a silicon content of 31.9\% elemental weight; the inset of Figure 2A shows photographic images of mesoporous $\mathrm{SiO}_{2}$ (I) and $\mathrm{PBN@SiO}_{2}$ (II). The XRD spectra of as-made $\mathrm{PBN} @ \mathrm{SiO}_{2}$ and mesoporous $\mathrm{SiO}_{2}$ are shown in Figure $2 \mathrm{E}(\mathrm{a}-\mathrm{b})$. The results for as-made $\mathrm{PBN@SiO} 2$ and mesoporous $\mathrm{SiO}_{2}$ demonstrate a broad peak, which is assigned to the 101 plane of amorphous $\mathrm{SiO}_{2}$ (Figure 2E(a)); additional peaks for as-made $\mathrm{PBN@SiO}_{2}$ are assigned to 220, 220 and 400 lattice planes of crystalline PBN. After exposure to the EETMSi-mediated PBN-laden formulation, an alteration in the $\mathrm{SiO}_{2}$ pore size was detected via BET analysis (Table 1).

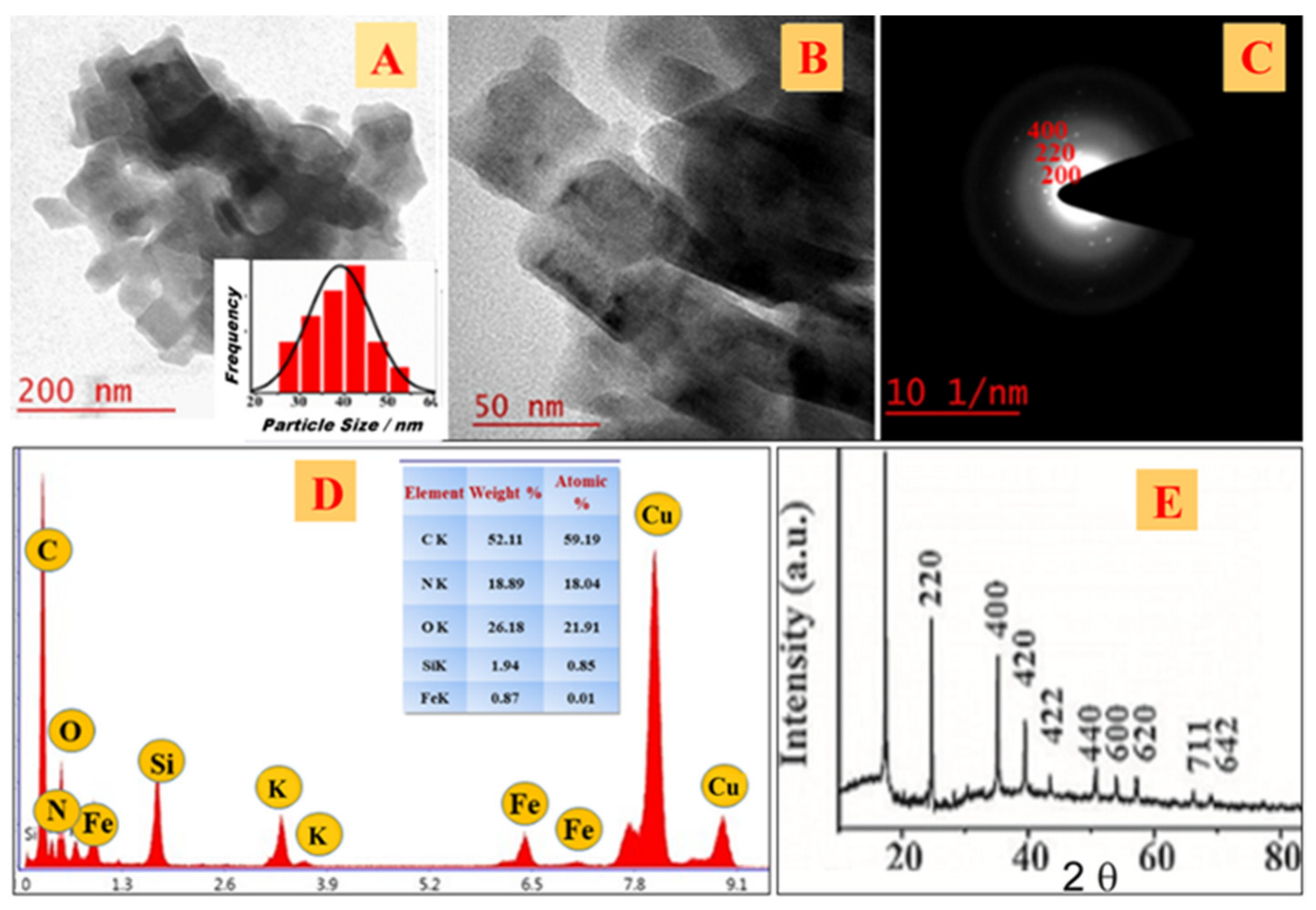

Figure 1. TEM images of PBN at different magnifications (A,B). Bar histogram displaying the particle size distribution curve of the nanoparticles (inset of Figure 1A). SAED pattern of as-synthesized particles (C), EDX profile with all the anticipated elements (D), XRD of EETMSi-functionalized PBN (E).

Table 1. Parameters calculated from BET nitrogen gas adsorption isotherm.

\begin{tabular}{ccc}
\hline Sample Name & $\begin{array}{c}\text { Surface Area } \\
\times \mathbf{1 0}^{\mathbf{4}} \mathbf{c m}^{\mathbf{2}} \mathbf{g}\end{array}$ & $\begin{array}{c}\text { Pore Size } \\
(\mathbf{n m})\end{array}$ \\
\hline $\mathrm{SiO}_{2}$ Bead & 474.8 & 6.1 \\
$\mathrm{~PB} @ S i O_{2}$ Bead & 426.8 & 4.3 \\
\hline
\end{tabular}

\subsubsection{PBN-Doped Mesoporous Silica Nanoparticles (PBN@MSNP)}

We also undertook the synthetic incorporation of PBN within mesoporous silica nanoparticles. Silica nanoparticles (MSNP) with an average particle size of $200 \mathrm{~nm}$ and a pore size of $6 \mathrm{~nm}$ were used for this purpose. The porous nanocomposite was obtained primarily in two steps: (a) surface functionalization of the matrix by EETMSi, followed by (b) the uniform distribution of metal precursor throughout the network and subsequent reduction to form nanoscale particles. The in situ growth of PBN was $\mathrm{pH}$ controlled. The soluble $\mathrm{Fe}^{3+}$ species easily adhered to the pore channels in the presence of capping agent EETMSi. The HRTEM micrograph of bare MSNPs (Figure 3a(A)) shows a porous skeleton of spherical morphology. Figure $3 a(B)$ shows PBN inside the mesoporous silica nanoparticles (encircled in red) [26]. The selected area electron diffraction (SAED) pattern of the corresponding hybrid nanoparticle assembly (PBN@MSNP) is shown in Figure 3a(C). 
The zeta potential value was obtained from dynamic light scattering (DLS) data to understand the solution stability of particles. As shown in Figure $3 a(D)$, the value of zeta potential is nearly $-23 \mathrm{mV}$ (i.e., towards the negative side); hence, the PBNPs are also negatively charged.
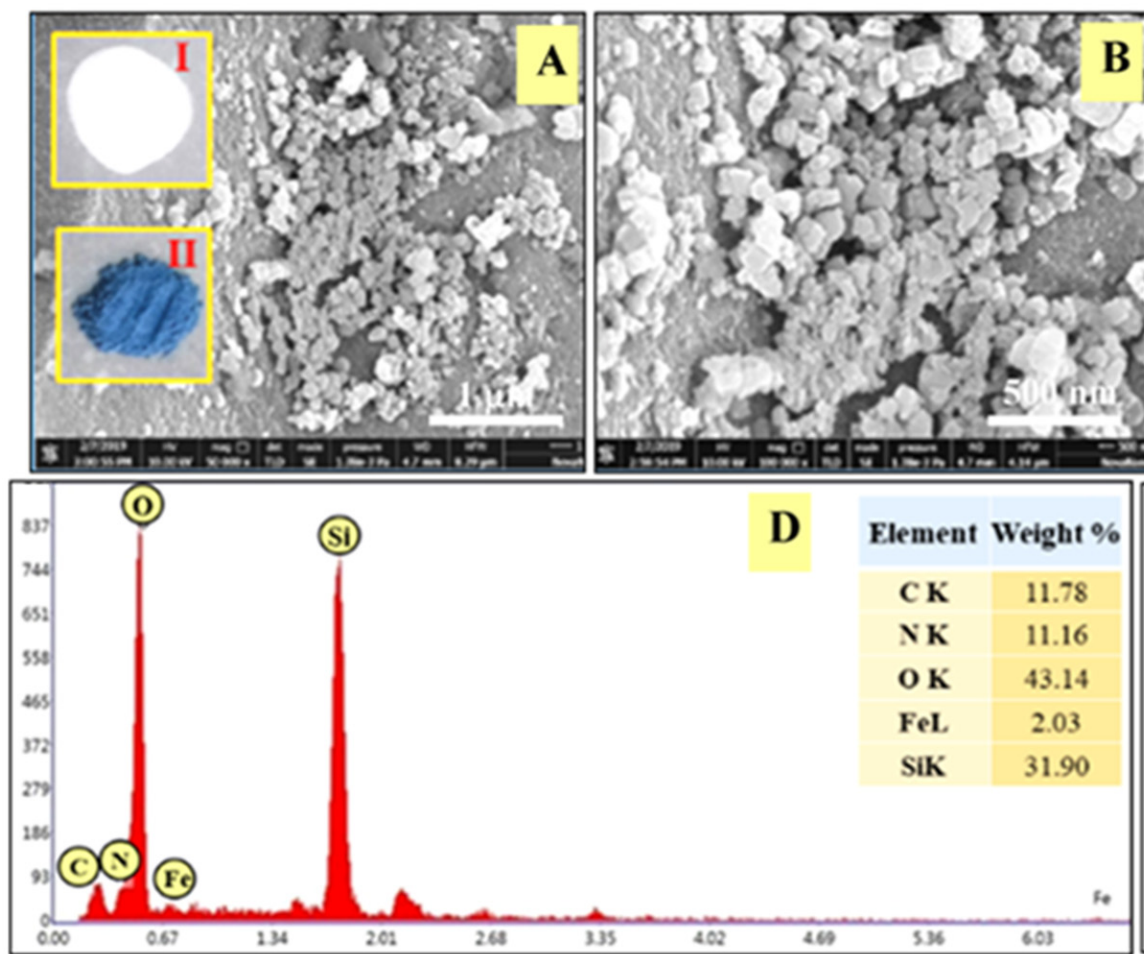
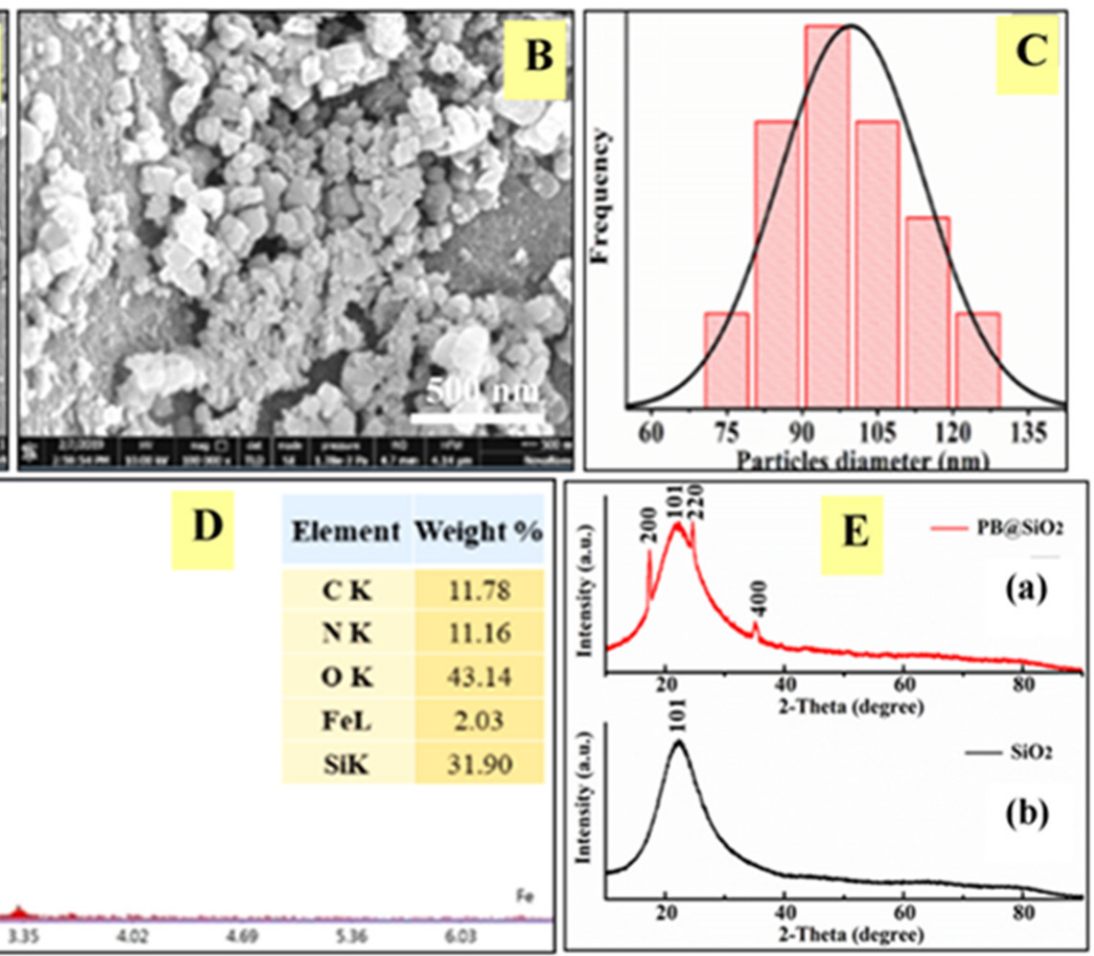

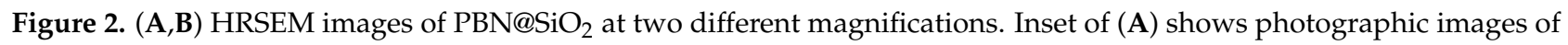
mesoporous silica (I) and PBN-inserted mesoporous silica (II). (C) The particle size distribution of PBN within mesoporous silica. (D) The EDX spectrum of PBN-inserted mesoporous silica. (E) XRD spectra of $\mathrm{SiO}_{2}$ (a) and $\mathrm{PBN}_{\mathrm{N}} @ \mathrm{SiO}_{2}$ (b).

The EDX spectrum of PBN@MSNPs is shown in Figure 3a(E). The EDX mapping of the organotrialkoxysilane-functionalized PBN@MSNPs with the elemental composition of (B) carbon, (C) nitrogen, (D) oxygen (E) iron, and (F) silicon is shown in Figure 3b. The crystallographic data for as-prepared PBN@MSNPs and blank MSNPs are shown in Figure $3 \mathrm{a}(\mathrm{F})$. The peaks indexed at $2 \theta$ values of $17.6^{\circ}(200), 24.3^{\circ}(220)$, and $37.8^{\circ}(400)$ indicated the successful insertion of crystalline PBN within the $\mathrm{SiO}_{2}$ matrix; per JCPDS \# $73-0687,17.4^{\circ}(200), 24.7^{\circ}(220), 35.3^{\circ}(400), 39.6^{\circ}(420)$, and $43.7^{\circ}(422), 50.0^{\circ}(440), 53.9^{\circ}$ (600), $57.2^{\circ}(620), 66.1^{\circ}(640), 68.9^{\circ}(642)$, and $77.2^{\circ}$ (820) can be indexed as the PB cubic space group Fm3m.

\subsection{FTIR Analysis of $\mathrm{PBN} @ \mathrm{SiO}_{2}$}

The peak at $2086 \mathrm{~cm}^{-1}$ in the FTIR spectrum (Figure 4A of PBN may be attributed to the $\mathrm{CN}$ stretching mode of the Fe(II)-C-N-(III)Fe moiety in PBN. The broad bands at $3402 \mathrm{~cm}^{-1}$ and $1642 \mathrm{~cm}^{-1}$ in the spectrum correspond to $\mathrm{OH}$-stretching and $\mathrm{H}_{2} \mathrm{O}$ bending mode of the interstitial water molecule, respectively, within the PBN lattice. The strong band near $2885-2990 \mathrm{~cm}^{-1}$ corresponds to the $\mathrm{C}-\mathrm{H}$ stretching vibration of $\mathrm{sp}^{2}$-hybridized carbon in cyclohexanone. 

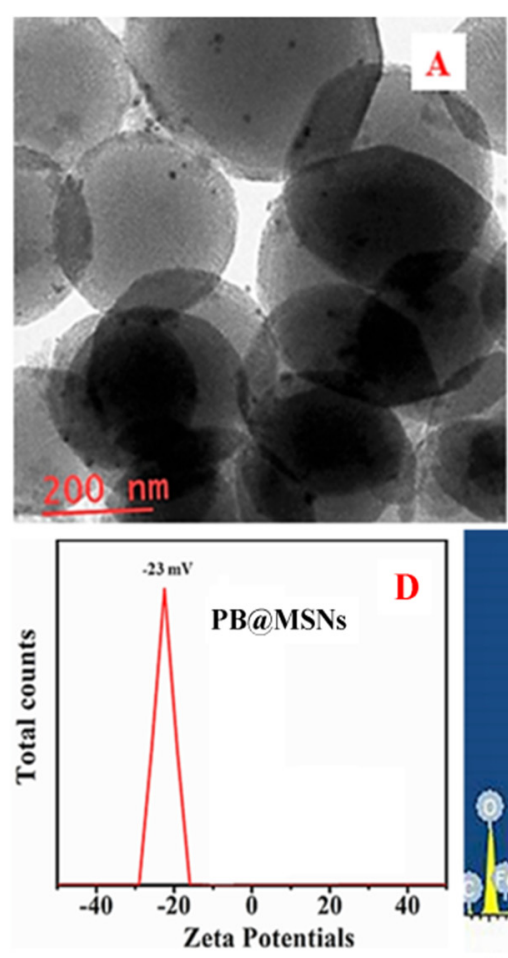
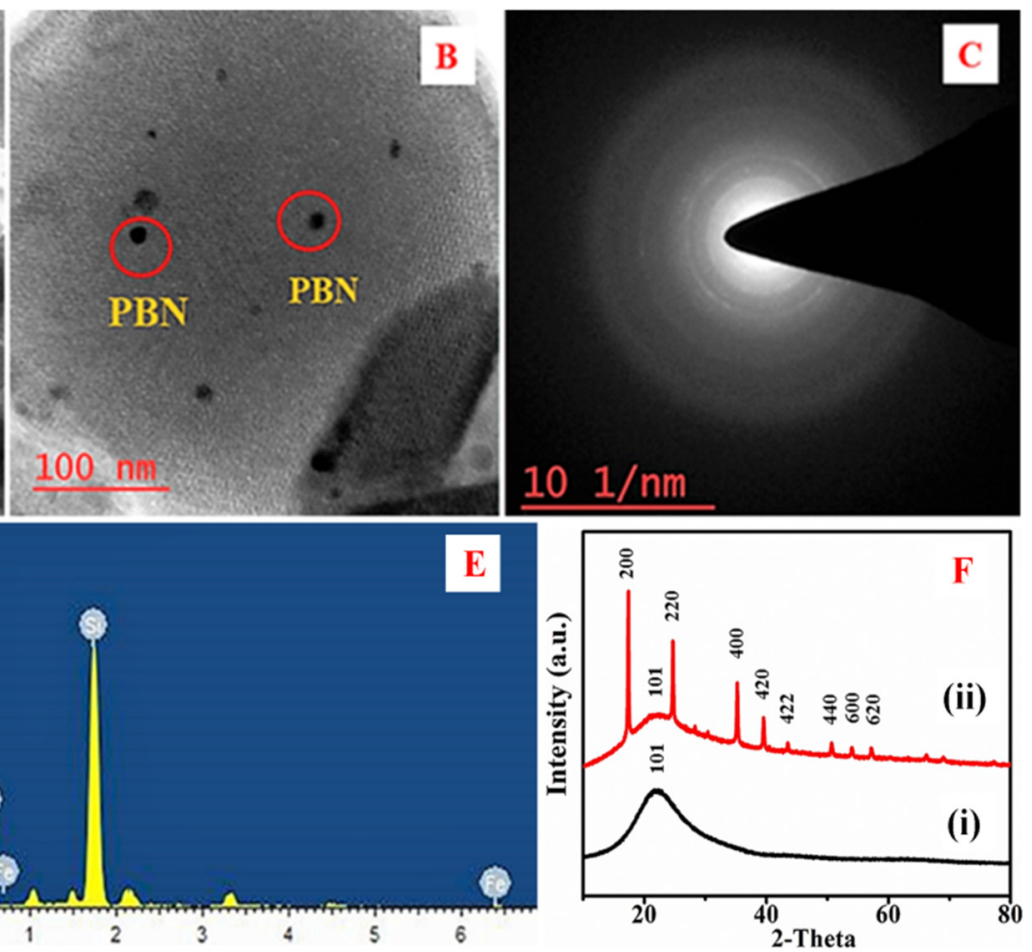

(a)
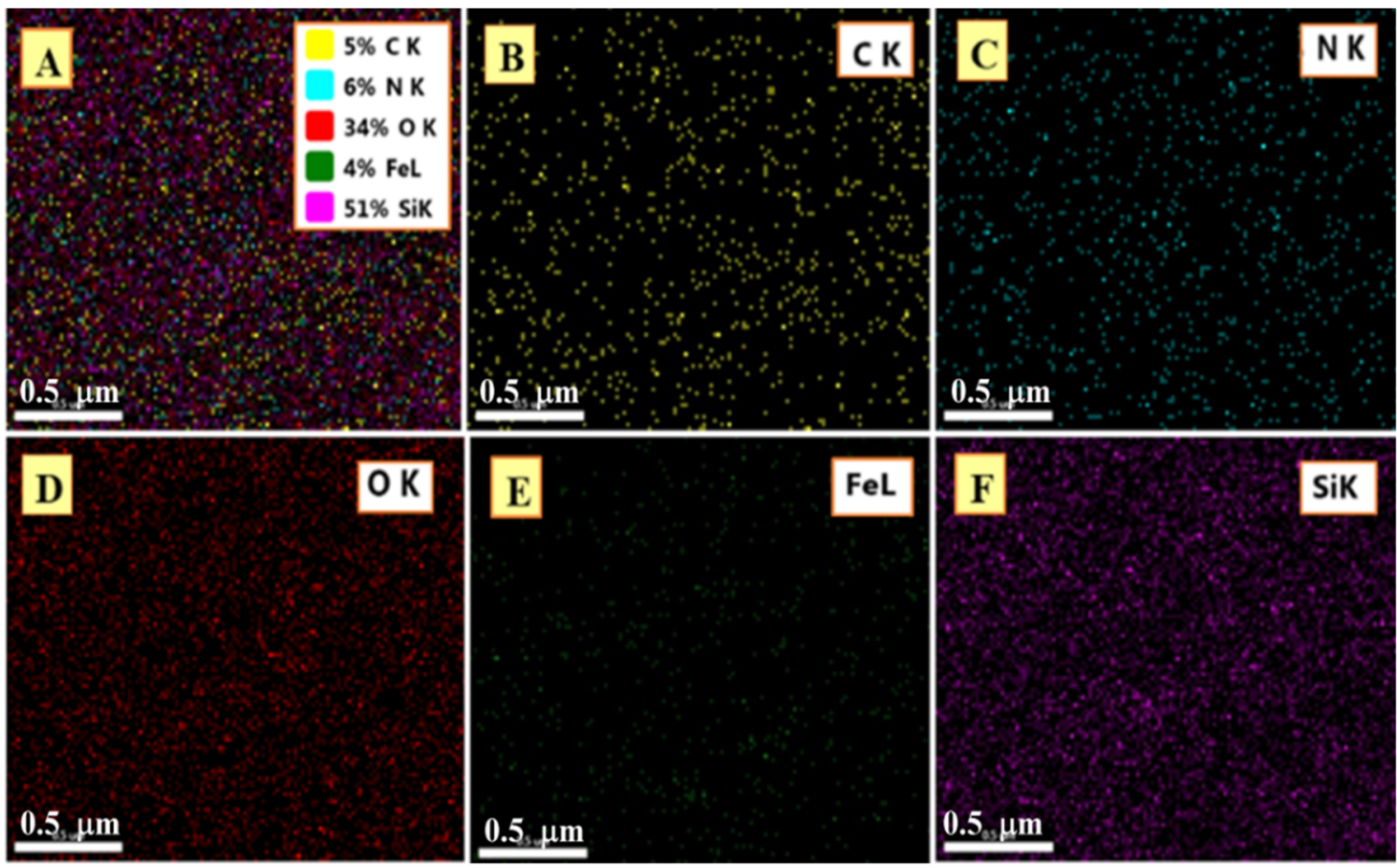

(b)

Figure 3. (a) (A) HRTEM image of organotrialkoxysilane-functionalized Prussian blue nanoparticles (PBN@MSN), (B) micrograph showing the magnified view of bulk-confined PBN (encircled in red) in mesoporous silica, (C) SAED pattern of the corresponding hybrid nanoparticle assembly (PBN@MSN), (D) stability profile of PBN@MSN in terms of zeta potential measurement, and (E) EDX spectrum of PBN@MSNP. (F) XRD profile for MSNPs (i) and as-synthesized PBN@MSNPs (ii). (b) (A) Mapping analysis of organotrialkoxysilane-functionalized Prussian blue nanoparticles with elemental composition (B) carbon, (C) nitrogen, (D) oxygen (E) iron, and (F) silicon. 

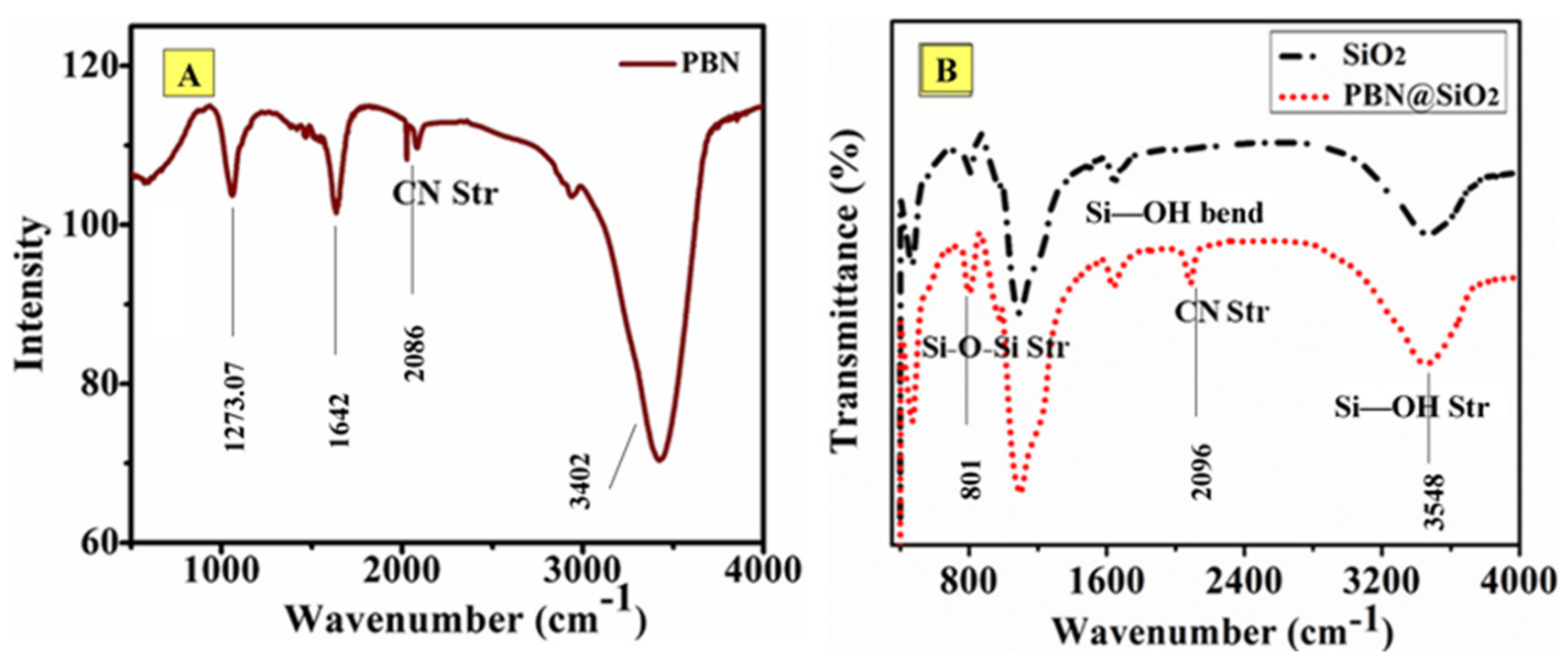

Figure 4. (A) FTIR spectrum of as-synthesized PBN; (B) FTIR spectra of (black line) $\mathrm{SiO}_{2}$ and (red line) as-synthesized $\mathrm{PBN} @ \mathrm{SiO}_{2}$.

The broad bands centered at $3548 \mathrm{~cm}^{-1}$ and at $1632 \mathrm{~cm}^{-1}$ are assigned to the stretching and bending vibrations of silanol groups $(\mathrm{Si}-\mathrm{OH})$, respectively, in the silica beads [27]. The bands at $1093 \mathrm{~cm}^{-1}$ and $801 \mathrm{~cm}^{-1}$ in the spectrum are associated with the anti-symmetric and symmetric stretching modes $(\mathrm{Si}-\mathrm{O}-\mathrm{Si})$ of $\mathrm{SiO}_{4}$ units. The prominent peak at $2096 \mathrm{~cm}^{-1}$ (Figure 4B is attributed to the stretching mode of Fe(II)-CN-(III)-Fe moiety in PBN [28] and indicates the successful formation of nanoparticles over $\mathrm{SiO}_{2}$.

\subsection{Fluorometric Study}

\subsubsection{Effect of the Addition of As(III) on the Fluorescent Intensity of Fluorescein}

Since PBN have already been established as light quenching material, the PBNmediated fluorescence quenching of fluorescein was evaluated. The impact of As(III) on fluorophore activity was studied via adding a different concentration of As(III) solution to a fixed Flo concentration. Subsequently, $0.01 \mathrm{~mL}$ of As(III) (10-320 ppm) and $10 \mu \mathrm{L}$ of Flo solution $(0.2 \mathrm{mM})$ were transferred into $2 \mathrm{~mL}$ of Milli-Q water and allowed to stand for $2 \mathrm{~min}$ at room temperature prior to fluorescence analysis. The fluorescence intensity of Flo was found to be enhanced as the function of As(III) (Figure 5A,B). At a lower As(III) concentration, a less pronounced enhancement phenomenon was observed. This result revealed that the extent of the interaction between Flo molecule and As(III) occurred to a higher extent at a higher As(III) concentration (up to 1.5 fold). The emission intensity was found to enhanced three-fold when the concentration of As(III) was elevated from 0.05 ppm to 2 ppm (effective concentration).
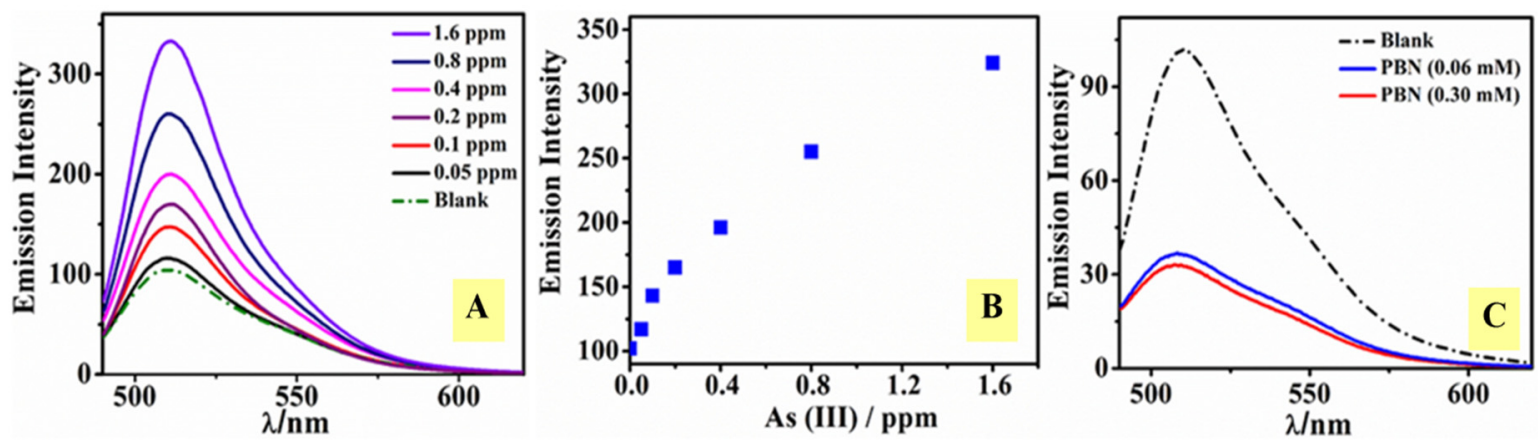

Figure 5. Fluorescence emission spectra of Flo (blank) in the presence of different As(III) concentrations from 0.05 ppm to $1.6 \mathrm{ppm}$ (A). Plot of fluorescence intensity of Flo $(0.2 \mathrm{mM})$ after exposure to a variable concentration $(0.05-1.6 \mathrm{ppm})$ of As(III) (B). Effect of PBN addition (0.06 mM, $0.3 \mathrm{mM})$ over Flo (0.2 mM) fluorescence (C). 


\subsubsection{Interaction of Fluorophore with PBN}

PBN were employed to observe the effect of the nano-sized particles over Flo. A constant amount of PBN nanosol $(0.3 \mathrm{mM})$ was added to a known concentration of Flo $(0.2 \mathrm{mM})$; the mixture was allowed to stand at room temperature for $2 \mathrm{~min}$. The results revealed that PBN quenched the fluorescence property of Flo as shown in Figure 5C. Furthermore, the effect of PBN concentration over the emission intensity of Flo was investigated. Mixtures containing various concentrations of PBN with Flo were used to understand the interaction of nanoparticles with the fluorophore. The mixtures (i) PBN $(0.06 \mathrm{mM})$ with Flo $(0.2 \mathrm{mM})$ and (ii) PBN $(0.3 \mathrm{mM})$ with Flo $(0.2 \mathrm{mM})$ were evaluated. It was shown that EETMSi functionalized PBN acted as a quencher for Flo since the intensity of the fluorophore was found to diminish in the presence of PBN (Figure 5C). On increasing the concentration of PBN from $0.06 \mathrm{mM}$ to $0.3 \mathrm{mM}$, only a small reduction in the emission intensity was observed (Figure 5C).

\subsubsection{Effect of As(III)/PBN System over Flo Intensity}

To understand the active role of PBN over As(III) interaction, we performed two experiments. In the first experiment, different concentrations of $\mathrm{As}(\mathrm{III})$ varying from $0.05 \mathrm{ppm}$ to $1.6 \mathrm{ppm}$ (effective concentration) were added to the fixed content of Flo $(0.3 \mathrm{mM})$; the Flo-As(III) system was then exposed to a constant amount of PBN $(0.3 \mathrm{mM})$ (as shown in Figure 6). In the second experiment, PBN $(0.3 \mathrm{mM})$ were initially added to the Flo solution $(0.2 \mathrm{mM})$; a variable concentration of $\mathrm{As}(\mathrm{III})$ between $0.05 \mathrm{ppm}$ and $1.6 \mathrm{ppm}$ (effective concentration) was then added to the PBN-Flo system (Figure 7). The substantial fluorescence quenching of the Flo-As(III) system in the presence of PBN was calculated using the relation $\mathrm{F}_{0} / \mathrm{F}$, where $\mathrm{F}_{0}$ and $\mathrm{F}$ denote the fluorescent intensity of the Flo-As(III) system in the absence and in the presence of PBN, respectively (Figure 8A). Similarly, the substantial fluorescence quenching of the Flo system in the presence of PBN was calculated using the relation $\mathrm{F}_{0} / \mathrm{F}$, where $\mathrm{F}_{0}$ denotes the fluorescence intensity of the Flo system in the absence of PBN and As(III), and F denotes the fluorescence intensity of Flo in the presence of PBN and As(III) (Figure 8B).
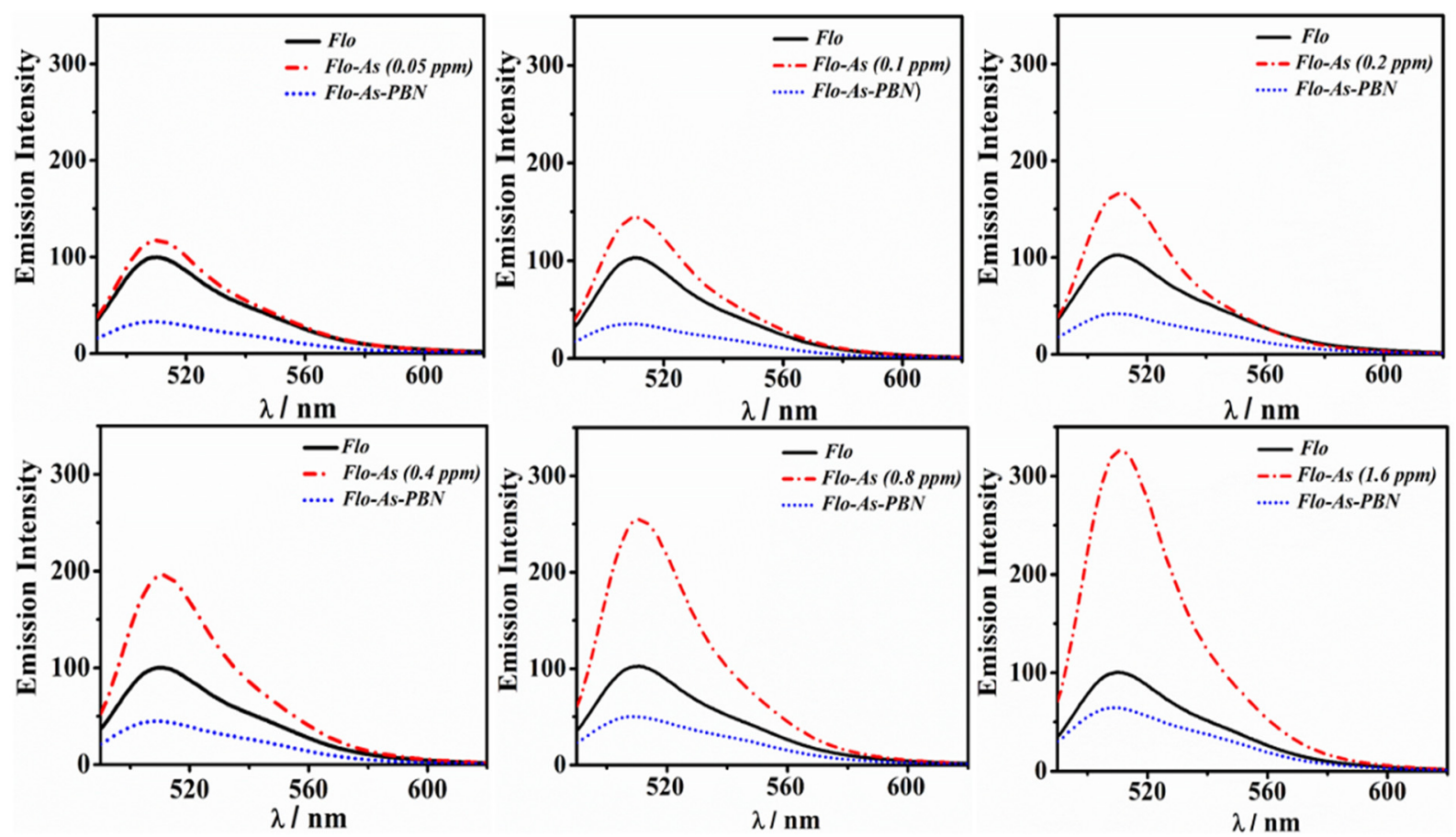

Figure 6. Study of the impact of PBN addition $\left(10^{-1}\right)$ over the emission intensity of Flo-As(III) system by varying the As(III) solution (0.05-1.6 ppm) and keeping a constant concentration of Flo (0.2 mM) and PBN (0.3 mM). 

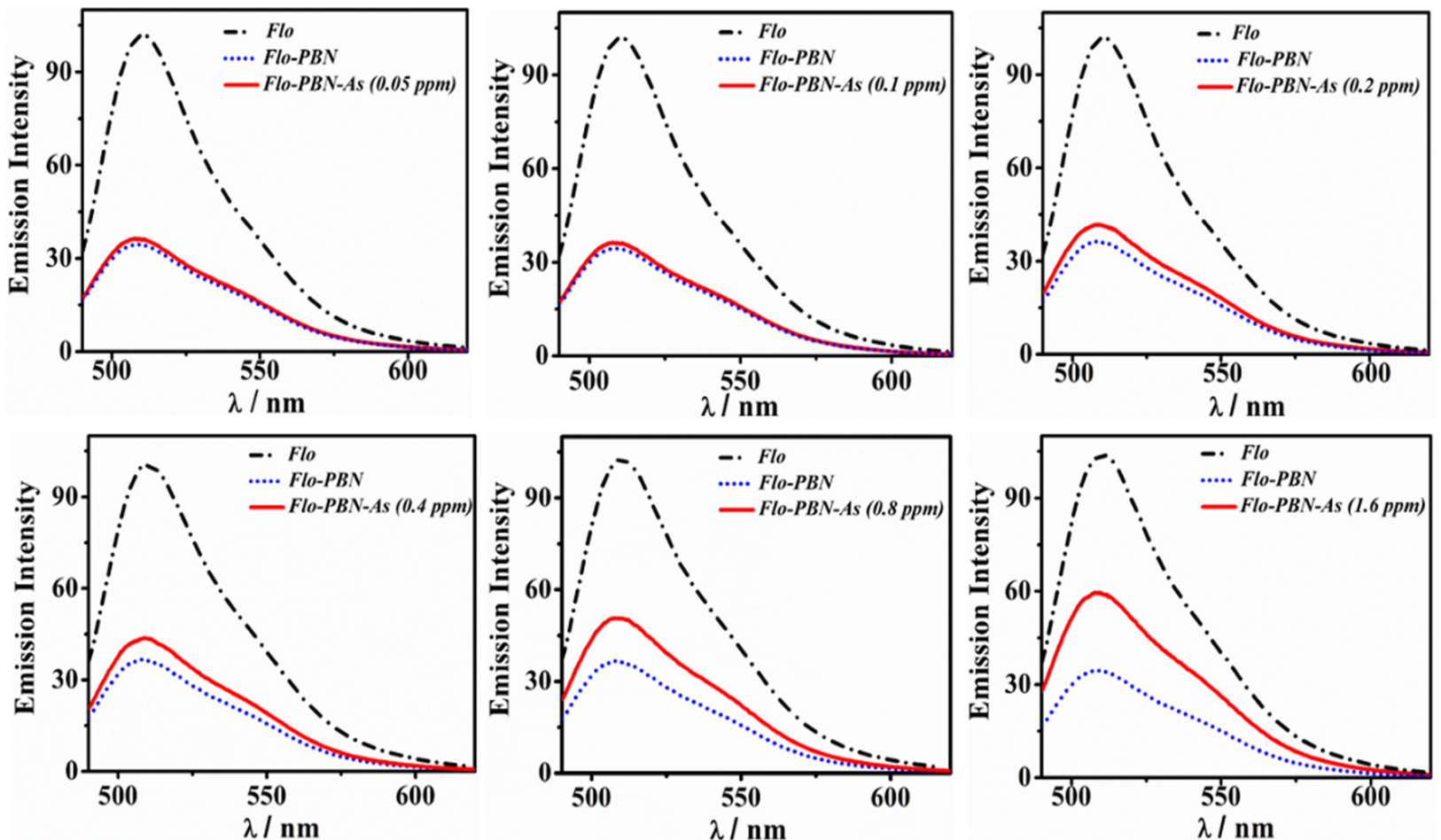

Figure 7. Study of the influence of As(III) addition over the emission spectra of the quenched Flo-PBN system by adding different concentrations of $\mathrm{As}(\mathrm{III})$ solution $(0.05-1.6 \mathrm{ppm})$ and keeping a constant concentration of Flo (0.2 $\mathrm{mM})$ and $\operatorname{PBN}(0.3 \mathrm{mM})$.
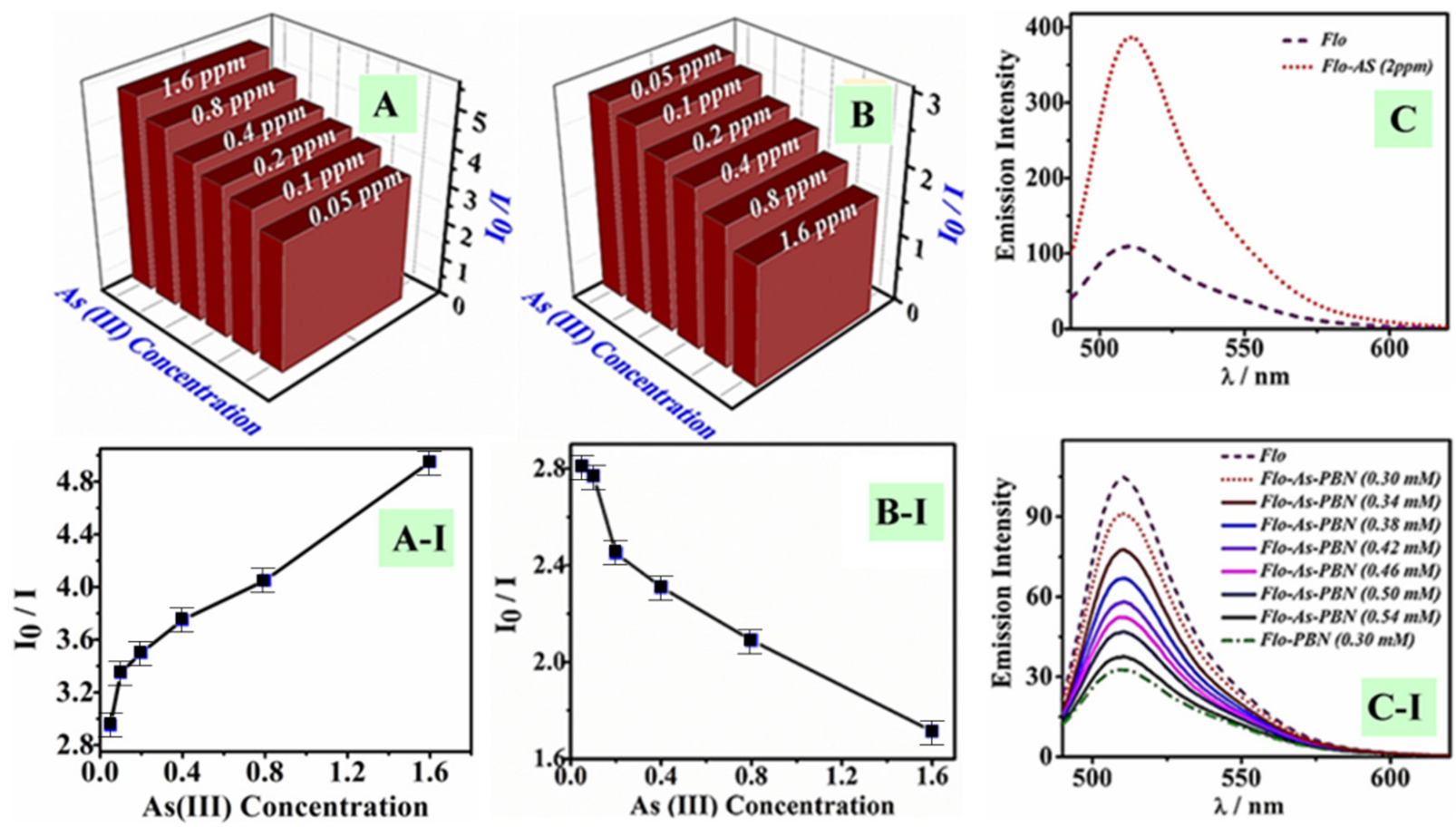

Figure 8. Bar diagram displaying fluorescence quenching (FQ) with respect to the variable concentration (effective concentration) of As(III) for the PBN@Flo-As(III) system (A) and the As(III)@PBN-Flo system (B). Plots of fluorescence intensity of the Flo-PBN system with respect to a variable content of As(III), showing concentration-dependent fluorescence quenching in both circumstances (A-I,B-I), with error bars representing the standard deviation. Emission spectra displaying the effect of adding 2 ppm of As(III) to the emission intensity of Flo (C). The required amount of PBN for complete quenching by adding various amounts of PBN to the Flo-As(III) system (C-I) and Flo. 
It was observed that As(III) interacted predominately with the available quantity of the PBN moiety; the residual available As(III) was associated with the rise in emission intensity after interacting with Flo (Figure 8C-I). The subsequent addition of PBN achieved maximum quenching after interacting with available As(III), as displayed in Figure 8C-I. This result indicates that $0.54 \mathrm{mM}$ PBN was sufficient to obtain complete interaction with $2 \mathrm{ppm}$ arsenite. A similar concentration of 2 ppm of As(III) was added to the Flo-PBN system, which contained both PBN and Flo. The results (Figure 8A-I and Figure 8B-I) showed a decrease in fluorescent intensity of Flo-As(III) and Flo as a function of PBN; PBN altered the fluorescence influencing properties of As(III). It is surmised that Prussian blue interacted with As(III) more efficiently than the Flo-As system throughout the fluorescence process. A separate experiment was performed to discover the PBN loading for complete removal of As(III) from a concentration of 2 ppm (effective concentration). For this study, primary emission spectra of Flo-As(III) were recorded while adding As(III) aqueous solution (2 ppm) to the blank solution containing Flo $(0.2 \mathrm{Mm})$ only (Figure $8 \mathrm{C})$. A similar concentration of 2 ppm of As(III) was added to the Flo-PBN system, which contained both PBN.

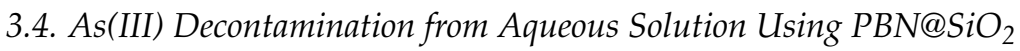

The heterogeneous $\mathrm{PBN} @ \mathrm{SiO}_{2}$ system was studied in order to understand the dynamic interaction occurring between As(III) and PBN. Accordingly, inexpensive and non-reactive silica beads were used for the modulation of active PBN in the formulation of the heterogeneous matrix. Heterogeneous methods are considered to play an influential role in catalysis due to their straightforward separation and large-scale applicability. For As(III) decontamination, the as-synthesized $\mathrm{PBN} @ \mathrm{SiO}_{2}(0.05 \mathrm{~g})$ was successfully packed in a column of $10 \mathrm{~mm}$ diameter. The standard As(III) solution (10 ppm) was prepared via adding an appropriate amount of sodium arsenite salt in Milli-Q water; $10 \mathrm{~mL}$ of the solution was passed through the $\mathrm{PBN} @ \mathrm{SiO}_{2}$ enclosed column. The fluorescence analysis of separated supernatant ( $\mathrm{PBN} @ \mathrm{SiO}_{2}$ processed) was performed using Flo $(0.2 \mathrm{mM})$ under similar conditions. In this study, $10 \mu \mathrm{L}$ of as-eluted supernatants $\left(\mathrm{PBN} @ \mathrm{SiO}_{2}\right.$ processed and unprocessed As(III) solution) were added separately with Flo and left to stand at room temperature for $2 \mathrm{~min}$. Their emission spectra were recorded to understand $\mathrm{PBN} @ \mathrm{SiO}_{2}$ interactions with As(III). Unprocessed As(III) solution was observed to enhance the emission intensity of Flo many-fold (Figure 9A) as compared to the $\mathrm{PBN} @ S i O_{2}$ processed $\mathrm{As}$ (III) solution (Figure 9B).

$\mathrm{PBN} @ \mathrm{SiO}_{2}$ was shown to significantly remove the As(III) from the contaminated solution. The ICP analysis of $\mathrm{PBN} @ S i O_{2}$ processed As(III) aqueous solution was performed to quantify the arsenic concentration in the solution. The result showed $0.0018 \mathrm{ppm}$ arsenic (As) content for the $\mathrm{PBN} @ \mathrm{SiO}_{2}$ processed $\mathrm{As}(\mathrm{III})$ solution. In addition, 0.13 ppm Fe content was also detected in the processed As(III) solution. The ICP analysis indicated that some of the iron species of PBN $\left(\left[\mathrm{Fe}^{\mathrm{III}}\left[\mathrm{Fe}^{\mathrm{II}}(\mathrm{CN})_{6}\right]\right)\right.$ leached out with the eluent during interaction with the As(III) species. To investigate the presence of active iron species in the eluent, we studied the addition of ferrous sulfate with active ferrous species $\left(\mathrm{Fe}^{+2}\right)$ to the colorless supernatant eluent. During this process, we added the ferric chloride-containing active ferric species to the colorless supernatant eluent. We observed that colorless supernatant changed immediately to an intense blue color (resembling the Prussian blue color) when ferric chloride was added. However, no such changes were observed when ferrous sulfate (containing $\mathrm{Fe}^{+2}$ ) was added.

We performed a fluorometric experiment in which supernatant (SN) was employed to observe its modulation of the Flo fluorescence properties. Fluorescent emission spectra were recorded after adding Flo $(10 \mu \mathrm{L})$ to $10 \mu \mathrm{L}$ of $\mathrm{PBN} @ \mathrm{SiO}_{2}$ processed supernatant $(\mathrm{SN})$. A small change in intensity $\left(I_{O}=102.23\right)$ was observed with respect to the Flo $\left(I_{O}=98.74\right)$ as seen in Figure 9C (1 and 2). A study that involved adding ferric chloride to the Flosupernatant (Flo-SN) mixture showed that the Flo fluorescence property was quenched $(I=31.73)$ when compared to Flo $(I=98.74)$, as shown in Figure $9 \mathrm{C}(3)$. Supernatant- 
containing ferrocyanide species had an instant interaction with the added ferric chloride, which instantly converted into PBN.
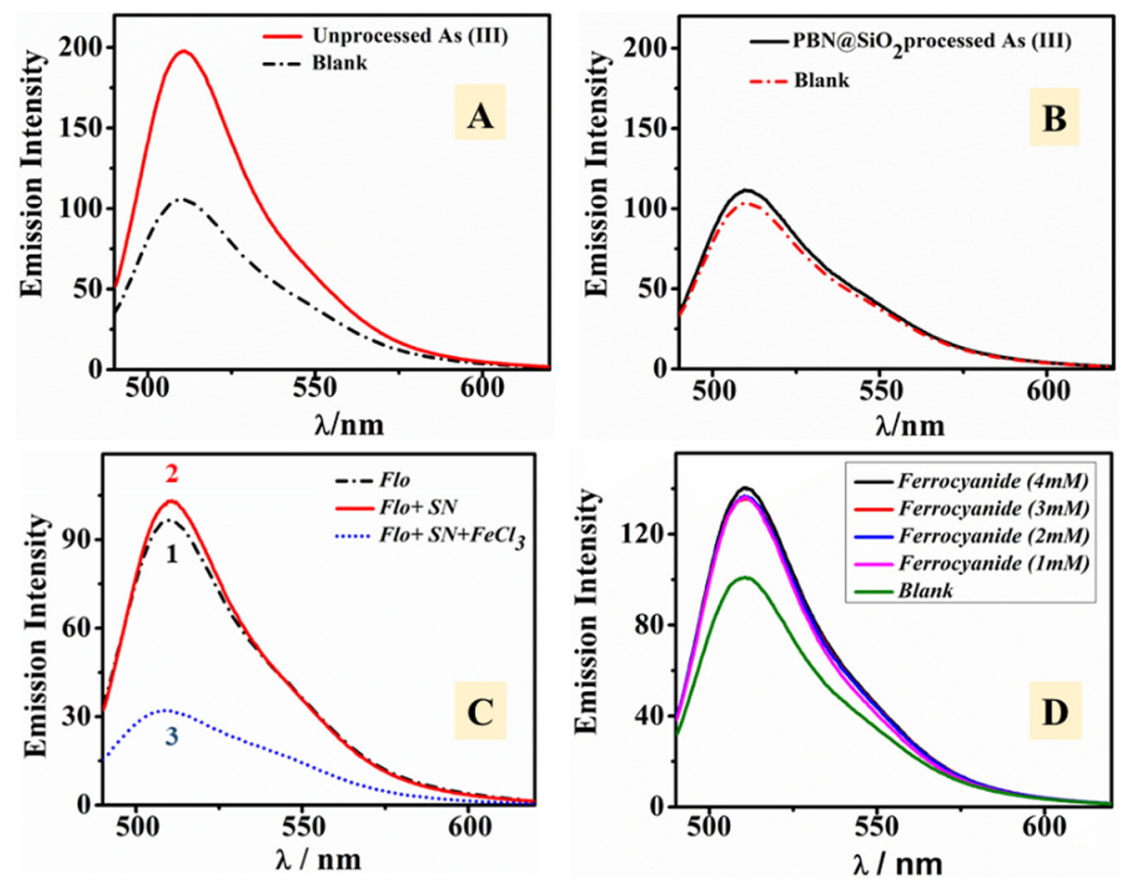

Figure 9. Fluorescence emission spectra of Flo with unprocessed (A) and PBN@SiO $\mathrm{O}_{2}$ processed (B) As(III) solution. Identification of ferrocyanide species in supernatant on the addition of ferric chloride via fluorescence quenching (C). Study of the effect of ferrocyanide species (1-4 mm) over Flo emission spectra (D).

To analyze the role of the residual ferrocyanide species in the supernatant over the emission spectra, a fluorescence experiment centered on the ferrocyanide concentration was conducted. We prepared and added different amounts ( $1 \mathrm{mM}$ to $4 \mathrm{mM})$ of ferrocyanide solution to a constant amount of Flo $(0.2 \mathrm{mM})$ to analyze the influence of the solution over the Flo emission intensity. Ferrocyanide acted as a weak enhancer (Figure 9D). These results indicate that the As(III) was supposed to undergo oxidation into arsenate in the presence of PBN. The iron species in the PBN undergo reduction into $\mathrm{Fe}^{+2}$ throughout the As(III) removal process. On the addition of active ferric species to the supernatant, an immediate reaction leads to the formation of PBN after the interaction with residual ferrous species. The collected PBN@SiO 2 was characterized with XPS to observe the significance of arsenic treatment over the $\mathrm{PBN} @ \mathrm{SiO}_{2}$ phase (as discussed in a subsequent section). Moreover, the resultant eluent was collected into separate vials and underwent HPLC analysis for the detection of arsenic species.

\subsection{HPLC Results on PBN@SiO $\mathrm{S}_{2}$ Treated Arsenic(III)}

All the separated species were noted in the ion-chromatogram at their respective retention time such as arsenobetaine $(\mathrm{AsB})$ at 2.17/2.42/2.55 $\mathrm{min}$, dimethylarsinic acid (DMA) at $3.57 \mathrm{~min}, \mathrm{As}(\mathrm{III})$ at 3.8/3.9 $\mathrm{min}$, and $\mathrm{As}(\mathrm{V})$ at $7.7 \mathrm{~min}$. The chromatogram shown in Figure 10A-D was obtained as the result of HPLC separation of the arsenic species after treatment with $\mathrm{PBN} @ \mathrm{SiO}_{2}$ at different $\mathrm{pH}$ values (2.2-8.5). HPLC analysis illustrates that the removal efficiency of As(III) ((Figure 10A) by $\mathrm{PBN}_{\mathrm{S}} \mathrm{SiO}_{2}$ increased from 33.52\% (Figure 10B) to 59.90\% (Figure 10C) with a pH increase from 2 to 6.5; this improved to 95.13\% (Figure 10D) under a mild alkaline condition ( $\mathrm{pH}-8.5)$. The ion chromatogram results also showed an insignificant peak at a retention time of $7.35 \mathrm{~min}$ ((Area\% $=1.4$ ) at $\mathrm{pH}=6.5$ and $($ Area $\%=9.09)$ at $\mathrm{pH}=8.5)$, which was associated with leaching of $\mathrm{As}(\mathrm{V})$ in an aqueous solution during the oxidation-adsorption process. All of the arsenic 
species (As(III), DMA, AsB) identified at various retention times along with their relative concentration in a HPLC environment are shown in Table 2.
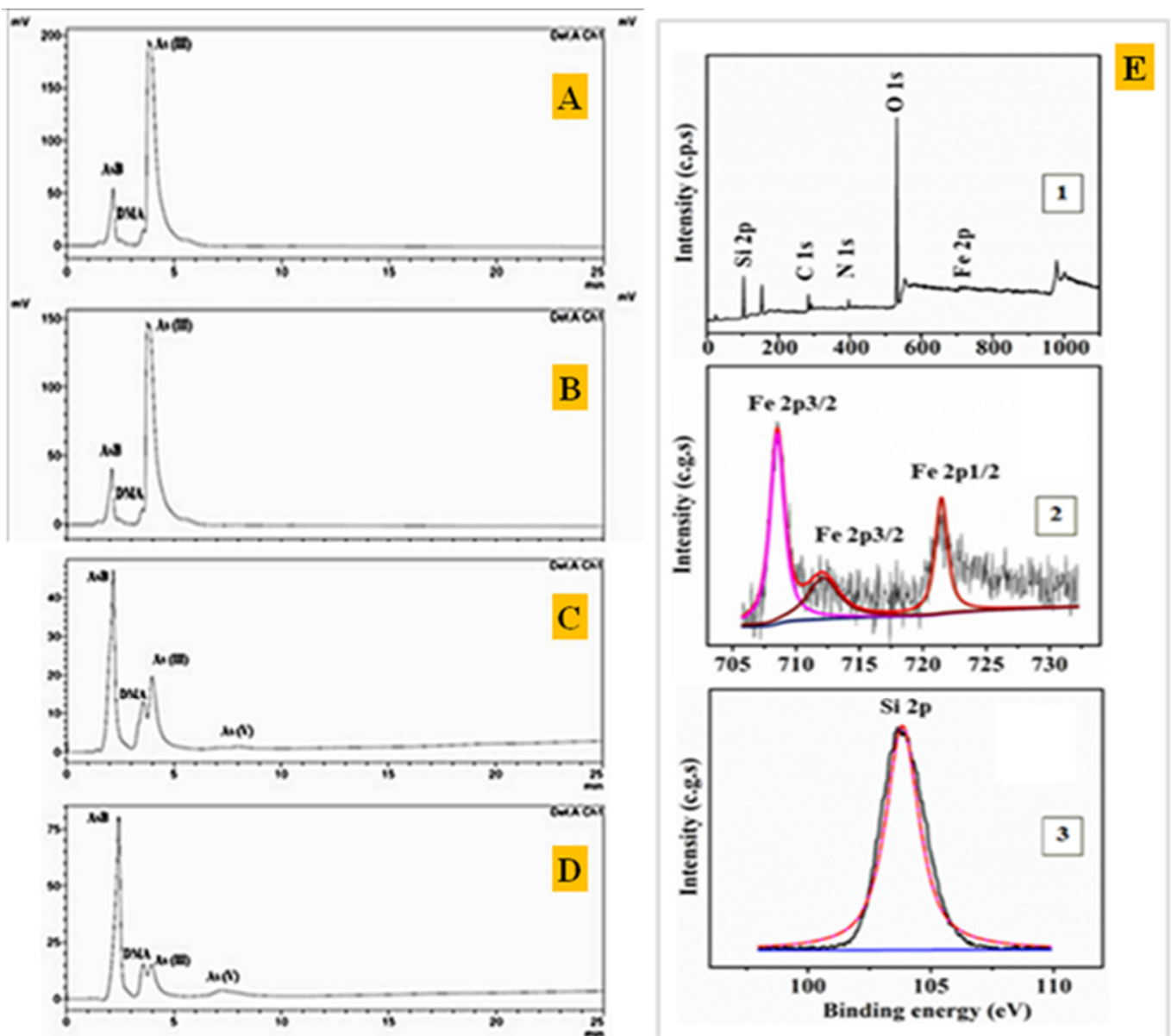

Figure 10. Ion chromatogram obtained during HPLC speciation of species present in the sample. (A) Standard As(III) (5 ppm) solution at $\mathrm{pH}=6.5)$. (B) Standard As(III) sample (5 ppm) after $\mathrm{PBN} @ \mathrm{SiO}_{2}$ treatment in acidic medium $(\mathrm{pH}=2)$. (C) As(III) standard solution (5 ppm) after $\mathrm{PBN} @ \mathrm{SiO}_{2}$ treatment in neutral medium $(\mathrm{pH}=6.5)$. (D) As(III) standard sample (5 ppm) after $\mathrm{PBN} @ \mathrm{SiO}_{2}$ treatment in alkaline medium $(\mathrm{pH}=8.5)$. (E) XPS analysis of $\mathrm{PBN} @ S i O_{2}$. (1) A complete survey scan with all recognized species. (2) $\mathrm{Fe}^{2+}$ and $\mathrm{Fe}^{3+}$ species XPS peak in $\mathrm{PBN} @ S i O_{2}$. (3) Identified $\mathrm{Si}(\mathrm{IV})$ chemical states in $\mathrm{SiO}_{2}$.

Table 2. All arsenic species (As(III), DMA, AsB) identified at different retention times along with their relative concentration during HPLC.

\begin{tabular}{|c|c|c|c|c|c|c|c|}
\hline Species & Description & $\begin{array}{l}\text { Molecular } \\
\text { Formula }\end{array}$ & $\begin{array}{l}\text { Height } \\
(\%)\end{array}$ & $\begin{array}{c}\text { Area } \\
(\%)\end{array}$ & $\begin{array}{l}\text { System } \\
\mathrm{pH}\end{array}$ & $\begin{array}{l}\text { Retention } \\
\text { Time }\end{array}$ & Figure \\
\hline \multirow[t]{3}{*}{$\mathrm{As}^{\mathrm{III}}$} & \multirow{3}{*}{$\begin{array}{l}\text { Sodium arsenite } \\
\qquad\left(\mathrm{NaAsO}_{2}\right)\end{array}$} & & 47.1 & 57.03 & 2.2 & $3.86 \mathrm{~min}$ & Figure 10B \\
\hline & & & 23.86 & 30.65 & 6.8 & $3.97 \mathrm{~min}$ & Figure 10C \\
\hline & & & 6.91 & 5.23 & 8.5 & $3.95 \mathrm{~min}$ & Figure 10D \\
\hline \multirow[t]{3}{*}{ AsB } & \multirow{3}{*}{$\begin{array}{l}\text { Arsenobetaine } \\
\text { (AsB) }\end{array}$} & & 45.56 & 34.39 & 2.2 & $2.55 \mathrm{~min}$ & Figure 10B \\
\hline & & & 58.29 & 49.74 & 6.8 & $2.17 \mathrm{~min}$ & Figure 10C \\
\hline & & & 70.02 & 56.95 & 8.5 & $2.42 \mathrm{~min}$ & Figure 10D \\
\hline \multirow[t]{3}{*}{ DMA } & \multirow{3}{*}{ Dimethylarsinic acid (DMA) } & & 6.85 & 4.21 & 2.2 & $3.58 \mathrm{~min}$ & Figure 10B \\
\hline & & & 15.81 & 16.21 & 6.8 & $3.57 \mathrm{~min}$ & Figure $10 \mathrm{C}$ \\
\hline & & & 13.45 & 11.79 & 8.5 & $3.57 \mathrm{~min}$ & Figure $10 \mathrm{D}$ \\
\hline
\end{tabular}


AsB, which frequently existed in the zwitterionic form due to the interaction between the positively charged arsenic and the negatively charged carboxylic group, starts to migrate immediately after interacting with the hydrophobic $\mathrm{C} 18 \mathrm{Shim}$-pack column. However, As(III) is a neutral species ( $\mathrm{pKa}=9.2)$ up to a $\mathrm{pH}$ of 8 , which eluents slowly with the solvent front. Consequently, negatively charged DMA and As(V) species feasibly eluent by a variety of interactions (e.g., $\mathrm{H}$ bonding and ion-exchange) along with hydrophobic effects. The obtained result was acquired after a total run time of $25 \mathrm{~min}$ and repeated twice to minimize the experimental error.

\subsection{XPS Analysis of PBN@SiO}

XPS survey scans indicated the presence of $\mathrm{Si}, \mathrm{O}, \mathrm{Fe}$, and $\mathrm{C}$ in blank $\mathrm{PBN} @ \mathrm{SiO}_{2}$ and As, $\mathrm{Si}, \mathrm{O}, \mathrm{Fe}$, and $\mathrm{C}$ in $\mathrm{As}(\mathrm{III})-\mathrm{PBN} @ \mathrm{SiO}_{2}$. The peaks were assigned as follows: $\mathrm{Fe} 2 \mathrm{p}_{3 / 2}$ $708 \mathrm{eV}$; Fe 2p $3 / 2-713 \mathrm{eV}$; Fe 2p $1 / 2-722 \mathrm{eV}$; As(III) $3 \mathrm{~d}-44.2 \mathrm{eV}$ and As(IV) $3 \mathrm{~d}-47 \mathrm{eV}$, respectively. The peak position of the $\mathrm{Si} 2 \mathrm{p}$ spectrum corresponds to a binding energy of $103.63 \mathrm{eV}$ and shows the characteristics of $\mathrm{Si}(\mathrm{IV})$ in a $\mathrm{SiO}_{2}$-type compound [29].

\subsubsection{Fe(II) and Fe(III) Identification in ${\mathrm{PBN} @ S_{2}}_{2}$}

After peak fitting, the spectrum can be de-convolved into three peaks. Figure 10E shows the XPS peaks centered on binding energies of 721.27 and $708.34 \mathrm{eV}$ for Fe $2 \mathrm{p}_{1 / 2}$ and $\mathrm{Fe} 2 \mathrm{p}_{3 / 2}$, respectively; these features are characteristic of the $\mathrm{Fe}^{+2}$ moiety in Prussian blue. In addition, a spectrum shows a peak at a binding energy of $712.12 \mathrm{eV}$, which corresponds to $\mathrm{Fe}^{+3}$ species. The position of these peaks is in good agreement with the results in the literature for the characteristic $\mathrm{Fe}^{+3}$ and $\mathrm{Fe}^{+2}$ components of Prussian blue compounds [30].

\subsection{2. $\mathrm{As}(\mathrm{III})-\mathrm{PBN} @ \mathrm{SiO}_{2}$ and $\mathrm{As}(\mathrm{V})-\mathrm{PBN} @ \mathrm{SiO}_{2}$}

The cation As(III) and the oxidized species As(V) detected on the $\mathrm{PBN} @ \mathrm{SiO}_{2}$ substrate with XPS after a decontamination process are shown in Figure 11. The binding energy values (in eV) for O (1s), Si (2p), Fe (2p), and N (1s) in $\mathrm{PBN} @ S i O_{2}$ and As- $\mathrm{PBN} @ \mathrm{SiO}_{2}$ are listed in Table 3. The XPS survey scan as shown in Figure 11D shows peaks at a binding energy of $49.03 \mathrm{eV}$, which are associated with the presence of $\mathrm{As}(\mathrm{V})$ and indicate the successful sorption of $\mathrm{As}(\mathrm{V})$ by $\mathrm{PBN} @ S i O_{2}$ [31]. The other peak located at $43.23 \mathrm{eV}$ is associated with the adsorption of $\mathrm{As}(\mathrm{III})$ over $\mathrm{SiO}_{2}$ prior to the oxidation process [32]. However, the peak positions observed for the $\mathrm{Fe}^{+3}$ and $\mathrm{Fe}^{+2}$ core level (2p) spectra of $\mathrm{PBN} @ \mathrm{SiO}_{2}$ are shifted slightly to a lower binding energy relative to the unreacted and unabsorbed $\mathrm{PBN} @ \mathrm{SiO}_{2}$ species. This shift in the peaks for $\mathrm{Fe}^{2+} 2 \mathrm{p}_{3 / 2}$ (binding energy of $708.19 \mathrm{eV}$ ) and $\mathrm{Fe}^{2+} 2 \mathrm{p}_{1 / 2}$ (binding energy of $721.42 \mathrm{eV}$ ) may be attributed to arsenic adsorption [33]. The shift in the peak position (with a reduction in intensity) of $\mathrm{Fe}^{+3} 2 \mathrm{p}_{3 / 2}$ (binding energy of $712.86 \mathrm{eV}$ ) relative to pure $\mathrm{PBN} @ S i O_{2}$ suggests the reduction of the material during arsenic oxidation [34]. The position of the characteristic peak of $\mathrm{Fe}^{+2}$ (binding energy of $55.04 \mathrm{eV}, 3 \mathrm{p}$ ) remained unchanged throughout the As(III) oxidation and adsorption process [31]. A peak emerged at a binding energy of $398.99 \mathrm{eV}$, which was attributed to the presence of nitrogen in the environment. Alterations in the peak position of $\mathrm{PBN} @ \mathrm{SiO}_{2}$ relative to that of As-PBN@SiO 2 were associated with chemical adsorption by $\mathrm{PBN} @ \mathrm{SiO}_{2}$ of arsenic species.

Table 3. XPS data of $\mathrm{PBN} @ \mathrm{SiO}_{2}$ and Arsenic-PBN@SiO 2 .

\begin{tabular}{|c|c|c|c|c|c|c|c|c|}
\hline \multirow{2}{*}{ Sample } & \multirow{2}{*}{$\operatorname{Si}(2 p)$} & $\mathrm{O}$ & $\mathrm{Fe}^{+3}$ & $\mathrm{Fe}^{+2}$ & $\mathrm{Fe}^{+2}$ & $\mathbf{N}$ & As(III) & $\operatorname{As}(\mathrm{V})$ \\
\hline & & 1s & $2 p_{3 / 2}$ & $2 p_{1 / 2}$ & $2 p_{3 / 2}$ & 1s & $3 d$ & $3 d$ \\
\hline $\mathrm{PBN} @ \mathrm{SiO}_{2}$ & 103.63 & 532.62 & 712.12 & 721.27 & 708.34 & 397.07 & - & - \\
\hline As-PBN@SiO & 103.49 & 531.99 & 712.86 & 721.42 & 708.19 & $\begin{array}{c}397.05 \\
\text { and } 398.99\end{array}$ & 43.23 & 49.03 \\
\hline
\end{tabular}



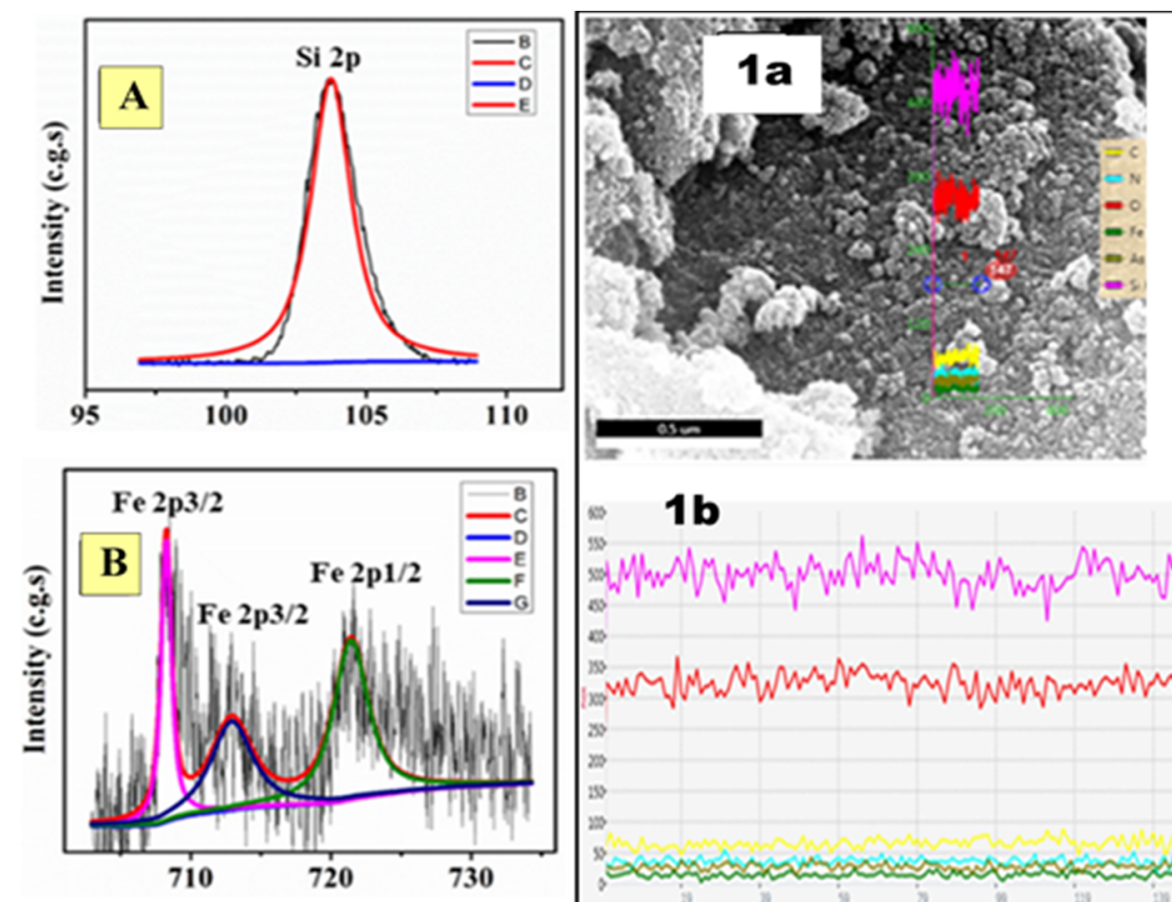

$1 \mathbf{b}$
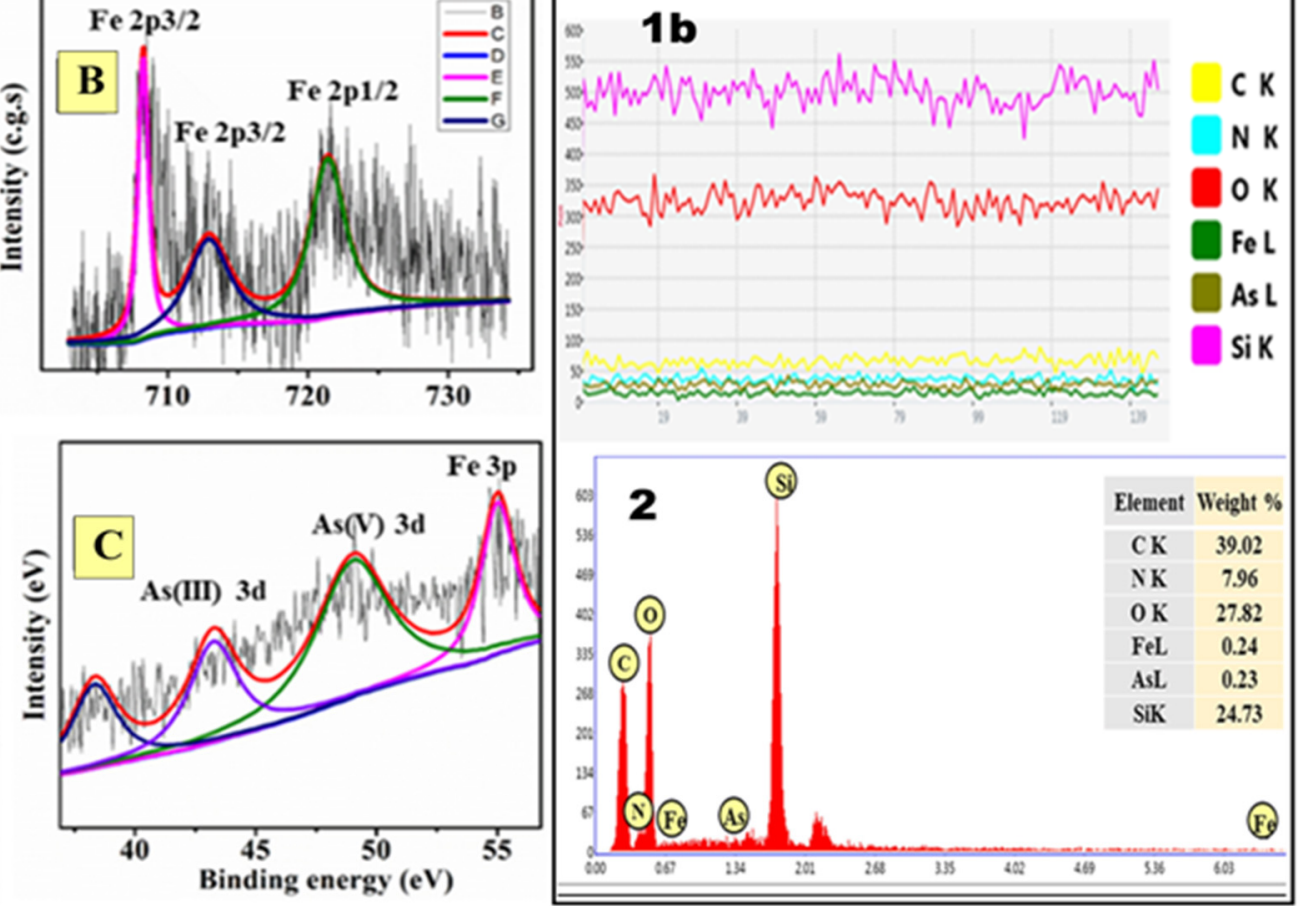

Figure 11. X-ray photoelectron spectrum of As-PBN@SiO ${ }_{2}$ after arsenic exposure. (A) Identified $\mathrm{Si}(\mathrm{IV})$ chemical states in $\mathrm{SiO}_{2}$. (B) $\mathrm{Fe}^{2+}$ and $\mathrm{Fe}^{3+}$ species XPS peak in $\mathrm{PBN} @ S i O_{2}$. (C) Arsenic species $(\mathrm{As}(\mathrm{V})$ and $\mathrm{As}(\mathrm{III}))$ at $\mathrm{PBN} @ \mathrm{SiO}_{2}$. (D) $(\mathbf{1} \mathbf{1}, \mathbf{1} \mathbf{b})$ EDX line scan measurement comprised of an inner $\mathrm{SiO}_{2}$ and an outer ferric hexacyanoferrate with As(III) enrichment over the $\mathrm{PBN} @ S i O_{2}$ surface. (2) EDX analysis shows all of the anticipated elements.

\subsection{Effect of $\mathrm{pH}$ on Arsenic Removal}

The results in Figure 10 illustrate the effects of $\mathrm{pH}$ on the removal of As(III) using $\mathrm{PBN} @ \mathrm{SiO}_{2}$. As can be observed, As(III) removal was dependent on $\mathrm{pH}$; the greatest removal efficiency occurred under moderate $\mathrm{pH}(\mathrm{pH}=6-9)$ and was found to diminish at highly acidic $\mathrm{pH}(\mathrm{pH}<3)$. As reported earlier, surfaces of silica beads were positively charged in highly acidic conditions and acquired a negative charge in the $\mathrm{pH}$ range of 3-10 [35]. Subsequently, moderate $\mathrm{pH}$ was found to be favorable for a sorbent surface since decreased protonation is supposed to enlarge the attraction force between the negatively charged $\mathrm{PBN} @ \mathrm{SiO}_{2}$ surface and the positively charged As(III) cationic species. This result is similar to earlier findings by Gupta et al. who reported a significant increase in As(III) adsorption onto iron oxide-coated quartz sand with an increase in $\mathrm{pH}$ from 4.5 to 7.5 [36]. At a highly acidic $\mathrm{pH}(<3)$, repulsion occurred between the positively charged adsorbent sites and the adsorbate species $\left(\mathrm{As}^{+3}\right)$, which prevented the adsorption and arsenic oxidation processes. No substantial rise in As(III) removal efficiency was observed with an elevation in $\mathrm{pH}$. 


\subsection{Analysis of PBN@SiO ${ }_{2}$ Surface through SEM-EDX after As(III) Remediation}

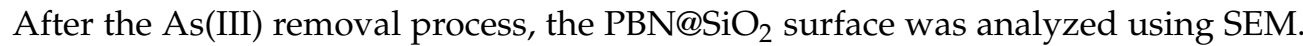
The result showed the change in morphology of PBN (cubic to spherical) after arsenic interaction (Figure 11E). The EDX results suggest that the material is comprised of an inner $\mathrm{SiO}_{2}$ chemistry and an outer ferric hexacyanoferrate $\left(\mathrm{Fe}^{+3}\left[\mathrm{Fe}^{+2}(\mathrm{CN})_{6}\right]\right)$ chemistry, with some As(III) enrichment over the $\mathrm{PBN} @ S i O_{2}$ surface. The presence of the anticipated elements was confirmed through EDX analysis.

\subsection{Recyclability and Proposed Mechanism}

It has been well established that Prussian blue is comprised of Fe metal in $\mathrm{Fe}^{+2}$ (low spin) and $\mathrm{Fe}^{+3}$ (high spin) states, which are linked via $\mathrm{CN}$ bridges. Prussian blue can undergo reduction to what is known as Prussian white $\left(\mathrm{Fe}^{\mathrm{II}}-\mathrm{C} \equiv \mathrm{N}-\mathrm{Fe}^{\mathrm{II}}\right)$ or oxidation to what is known as Prussian yellow ( $\mathrm{Fe}^{\mathrm{III}}-\mathrm{C} \equiv \mathrm{N}-\mathrm{Fe}^{\mathrm{III}}$ ) $[37,38]$. Reduction of Prussian blue to Prussian white on the surface of silica gel was found to facilitate the As(III) oxidation to $\mathrm{As}(\mathrm{V})$ and their subsequent removal. Conversion of $\mathrm{Fe}^{3+}$ to $\mathrm{Fe}^{+2}$ was shown during the decontamination in PBN and validate the altered chemical environment due to arsenic interactions. The addition of ferric chloride to the white-blue colored arsenite-treated $\mathrm{PBN} @ \mathrm{SiO}_{2}$ residue instantly generated a blue color; this phenomenon is attributed to the conversion of hexacyanoferrate $\left[\mathrm{Fe}^{\mathrm{II}}(\mathrm{CN})_{6}\right]$ species of $\mathrm{K}_{2}\left[\mathrm{Fe}^{\mathrm{II}} \mathrm{Fe}^{\mathrm{II}}(\mathrm{CN})_{6}\right]$ into Prussian blue $\left(\mathrm{K}\left[\mathrm{Fe}^{\mathrm{III}} \mathrm{Fe}^{\mathrm{II}}(\mathrm{CN})_{6}\right]\right)$ through the interaction with ferric species (ferric chloride). The reaction during Prussian blue synthesis has been shown as:

$$
4 \mathrm{~K}_{2}\left[\mathrm{Fe}^{\mathrm{II}} \mathrm{Fe}^{\mathrm{II}}(\mathrm{CN})_{6}\right]+4 \mathrm{FeCl}_{3} 4\left(\mathrm{~K}\left[\mathrm{Fe}^{\mathrm{III}} \mathrm{Fe}^{\mathrm{II}}(\mathrm{CN})_{6}\right]\right)+4 \mathrm{KCl}
$$

The variation of surface charge of $\mathrm{SiO}_{2}$ with a change in $\mathrm{pH}$ was found to be the fundamental framework for PBN activity over the course of arsenic removal.

\subsection{Mechanism of PBN Based Fluorescence Sensing of As(III)}

The findings as shown in Figures 4-6 revealed an analyte-dependent intervalence transition in iron hexacyanoferrate $\left[\mathrm{Fe}^{\mathrm{III}}{ }_{4}\left[\mathrm{Fe}^{\mathrm{II}}(\mathrm{CN})_{6}\right]_{3}\right]$ between $\mathrm{Fe}^{2+}$ and $\mathrm{Fe}^{3+}$ as shown below:

$$
\mathrm{Fe}^{2+}+\mathrm{Fe}^{3+}+\text { light energy } \rightarrow \mathrm{Fe}^{3+}+\mathrm{Fe}^{2+}
$$

The intervalence transition may be evaluated based on changes to the absorption spectrum. The fluorescein-PBN interaction is associated with fluorescence resonance energy transfer as recently described [39,40]; this material is capable of quenching the emitted fluorescence of fluorescein. When PBN undergo interaction with As(III), there is a conversion of PBN into Prussian white nanoparticles, followed by a conversion of $\mathrm{As}(\mathrm{III})$ to $\mathrm{As}(\mathrm{V})$; thus, the quenching ability is lost. The Prussian white nanoparticles can further be converted into PBN after treating the same with acid as discussed above. This scheme provides an effective and inexpensive method for PBN-mediated removal of As(III) udermvisible light.

\subsection{Characterization of Recyclable PBN@SiO 2}

After arsenic elimination, the recycled $\mathrm{PBN} @ \mathrm{SiO}_{2}$ was investigated with XRD, SEM,

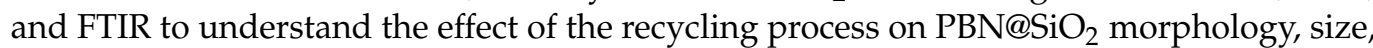
and crystallinity. An SEM image of the recycled PBN@SiO ${ }_{2}$ is shown in Figure 12. More spherical-shaped than cube-shaped particles were observed; the aggregation of PBN with no precise shape was also observed. XRD analysis demonstrated a shifting inward of the peak position $(\theta)$ as compared with the unused $\mathrm{PBN@SiO} 2$. The presence of anticipated elements was identified via EDX analysis. In addition, characteristic $\mathrm{CN}$ stretching in PBN was noted; this feature was noted at a considerably lower wavenumber $\left(2054 \mathrm{~cm}^{-1}\right)$, which is attributed to particle aggregation [39]. The PBN characteristics before and after the recycling process as obtained from XRD, SEM, and FTIR analysis are listed in Table 4. 


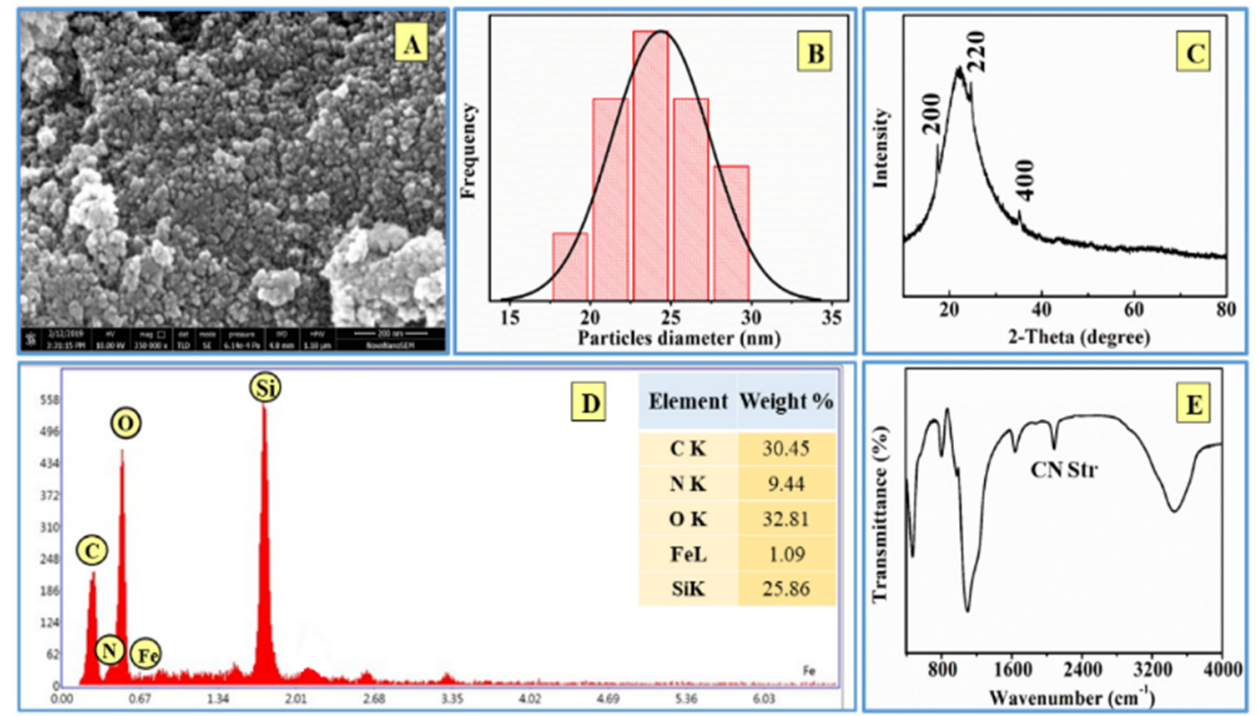

Figure 12. Analysis of recycled $\mathrm{PBN} @ \mathrm{SiO}_{2}$ following acid treatment. (A) An alteration in nanoparticle morphology as identified through SEM imaging, (B) A decrease in particle size $(26 \mathrm{~nm})$ as calculated from the displayed histogram, (C) Minor shift in peak position with similar planes as identified through XRD analysis, (D) Spectrum with the entire anticipated element as detected by EDX, (E) Shift in $\mathrm{CN}$ stretching peak observed using FTIR.

Table 4. Table with HRSEM, XRD and FTIR data displaying the variations between unused and recycled $\mathrm{PBN} @ \mathrm{SiO}_{2}$.

\begin{tabular}{cccc}
\hline Analysis & Property & Unused PBN@SiO & Recycled PBN@SiO \\
\hline & & Nanocubic $(82 \%)$ & Nanocubic $(19 \%)$ \\
HRSEM & Shape & and Spherical $(18 \%)$ & and Spherical (81\%) \\
HRSEM & Size & $70-20 \mathrm{~nm}$ & $17-26 \mathrm{~nm}$ \\
XRD & 2-Theta (Planes) & $17.6(200), 24.3(220), 37.83(400)$ & $17.4(200), 24.6(220), 35.12(400)$ \\
FTIR & CN Str. & $2096 \mathrm{~cm}^{-1}$ & $2054 \mathrm{~cm}^{-1}$ \\
\hline
\end{tabular}

\section{Conclusions}

PBN are a light-sensitive material that is processed through functional alkoxysilaneand cyclohexanone-mediated conversion of a single precursor, potassium hexacyanoferrate. The synthetic incorporation of PBN within mesoporous silica $\left(\mathrm{PBN} @ \mathrm{SiO}_{2}\right)$ was also studied; the morphology of these particles was characterized using TEM, SEM, XRD, and XPS. The as-made PBN were studied as a fluorescent quencher. The quenching ability of the materials is found to be a function of arsenic(III) concentration; this result suggested a novel application of PBN for fluorescence sensing of arsenic. In addition, XPS studies confirmed that arsenic is adsorbed on $\mathrm{PBN}_{\mathrm{S}} \mathrm{SiO}_{2}$ as arsenite $(\mathrm{As}(\mathrm{III}))$ and arsenate $(\mathrm{As}(\mathrm{V}))$ irrespective of the initial oxidation state of the material; this result indicated a novel application of PBN for the removal of arsenic(III) from a given sample.

Author Contributions: Conceptualization, P.C.P., S.S. and R.J.N.; methodology, P.C.P., S.S. and and R.J.N.; software, P.C.P., S.S. and R.J.N.; validation, P.C.P., S.S. and R.J.N.; formal analysis, P.C.P., S.S. and R.J.N.; investigation, P.C.P., S.S. and R.J.N.; resources, P.C.P., S.S. and R.J.N.; data curation, P.C.P., S.S. and R.J.N.; writing-original draft preparation, P.C.P., S.S. and R.J.N.; writing-review and editing, P.C.P., S.S. and R.J.N.; visualization, P.C.P., S.S. and R.J.N.; supervision, P.C.P., S.S. and R.J.N.; project administration, P.C.P., S.S. and R.J.N.; funding acquisition, P.C.P., S.S. and R.J.N. All authors have read and agreed to the published version of the manuscript.

Funding: This research was funded by [SERB, DST and DRDO] grant number [VJR/2017/000034 and LSRB-316 respectively]. 
Institutional Review Board Statement: The study was conducted according to the guidelines of the Declaration of Indian Institute of Technology (BHU), and approved by the Institutional Review Board.

Informed Consent Statement: Informed consent was obtained from all subjects involved in the study.

Data Availability Statement: Data supporting reported results can be found in the laboratory of Prof. Prem C Pandey of IIT(BHU). https: / /itbhu.ac.in/dept/apc/people/faculty.

Acknowledgments: The authors acknowledge IIT (BHU), Varanasi for financial assistance. Thanks are given to SERB for the VAJRA Fellowship and DRDO for granting LSRB-316.

Conflicts of Interest: The authors declare that they have no known competing financial interests or personal relationships that influence the work reported in this paper.

\section{References}

1. NRC. Subcommittee to Update the 1999 Arsenic in Drinking Water Report, Committee on Toxicology; NRC: Washington, DC, USA, 2002.

2. Nriagu, J.O.; Azcue, J. Arsenic in the Environment. Part I: Cycling and Characterization; John Wiley \& Sons: New York, NY, USA, 1994; Volume 26.

3. Roberts, L.C.; Hug, S.J.; Ruettimann, T.; Billah, M.; Khan, A.W.; Rahman, M.T. Arsenic Removal with Iron(II) and Iron(III) in Waters with High Silicate and Phosphate Concentrations. Environ. Sci. Technol. 2004, 38, 307-315. [CrossRef] [PubMed]

4. Holm, T.R. Effects of $\mathrm{CO}_{3}{ }^{2-}$ /bicarbonate, $\mathrm{Si}$, and $\mathrm{PO}_{4}{ }^{3-}$ on Arsenic sorption to HFO. J. Am. Water Work. Assoc. 2002, 94, 174-181. [CrossRef]

5. Jain, C.; Ali, I. Arsenic: Occurrence, toxicity and speciation techniques. Water Res. 2000, 34, 4304-4312. [CrossRef]

6. Edwards, M. Chemistry of arsenic removal during coagulation and Fe-Mn oxidation. J. Am. Water Work. Assoc. 1994, 86, 64-78. [CrossRef]

7. Shih, M.-C. An overview of arsenic removal by pressure-driven membrane processes. Desalination 2005, 172, 85-97. [CrossRef]

8. Pandey, P.C.; Pandey, A.K. Tetrahydrofuran hydroperoxide mediated synthesis of Prussian blue nanoparticles: A study of their electrocatalytic activity and intrinsic peroxidase-like behavior. Electrochim. Acta 2014, 125, 465-472. [CrossRef]

9. Pandey, P.C.; Singh, S.; Sawant, S.N. Functional alkoxysilane mediated controlled synthesis of Prussian blue nanoparticles, enabling silica alginate bead development; nanomaterial for selective electrochemical sensing. Electrochim. Acta 2018, 287, 37-48. [CrossRef]

10. Karyakin, A.A.; Karyakina, E.E.; Gorton, L. Amperometric biosensor for glutamate using Prussian blue-based "artificial peroxidase" as a transducer for hydrogen peroxide. Anal. Chem. 2000, 72, 1720-1723. [CrossRef] [PubMed]

11. Robin, M.B. The Color and Electronic Configurations of Prussian Blue. Inorg. Chem. 1962, 1, 337-342. [CrossRef]

12. Pintado, S.; Goberna-Ferron, S.; Escudero-Adan, E.C.; Galan-Mascaros, J.R. Fast and persistent electrocatalytic water oxidation by Co-Fe Prussian blue coordination polymers. J. Am. Chem. Soc. 2013, 135, 13270-13273. [CrossRef]

13. Qiu, J.-D.; Peng, H.-Z.; Liang, R.-P.; Li, J.; Xia, X.-H. Synthesis, Characterization, and Immobilization of Prussian Blue-Modified Au Nanoparticles: Application to Electrocatalytic Reduction of $\mathrm{H}_{2} \mathrm{O}_{2}$. Langmuir 2007, 23, 2133-2137. [CrossRef] [PubMed]

14. Karyakin, A.A.; Puganova, E.A.; Budashov, I.A.; Kurochkin, I.N.; Karyakina, E.E.; Levchenko, V.A.; Matveyenko, V.N.; Varfolomeyev, S.D. Prussian blue based nanoelectrode arrays for $\mathrm{H}_{2} \mathrm{O}_{2}$ detection. Anal. Chem. 2004, 76, 474-478. [CrossRef]

15. Pandey, P.C.; Singh, S.; Walcarius, A. Palladium-Prussian blue nanoparticles; as homogeneous and heterogeneous electrocat-alysts. J. Electroanal. Chem. 2018, 823, 747-754. [CrossRef]

16. Itaya, K.; Uchida, I.; Neff, V.D. Electrochemistry of polynuclear transition metal cyanides: Prussian blue and its analogues. Acc. Chem. Res. 1986, 19, 162-168. [CrossRef]

17. Han, L.; Yu, X.-Y.; Lou, X.W. Formation of Prussian-Blue-Analog Nanocages via a Direct Etching Method and their Conversion into Ni-Co-Mixed Oxide for Enhanced Oxygen Evolution. Adv. Mater. 2016, 28, 4601-4605. [CrossRef] [PubMed]

18. Pandey, P.C.; Pandey, A.K. Electrochemical sensing of dopamine and pyrogallol on mixed analogue of Prussian blue nano-particles modified electrodes-Role of transition metal on the electrocatalysis and peroxidasemimetic activity. Electrochim. Acta 2013, 109, 536-545. [CrossRef]

19. Pandey, P.C.; Pandey, A.K. Novel synthesis of super peroxidase mimetic polycrystalline mixed metal hexacyanoferrates nanoparticles dispersion. Analyst 2013, 138, 2295-2301. [CrossRef] [PubMed]

20. Pandey, P.C.; Pandey, A.K. Novel synthesis of Prussian blue nanoparticles and nanocomposite sol: Electro-analytical ap-plication in hydrogen peroxide sensing. Electrochim. Acta 2013, 87, 1-8. [CrossRef]

21. Pandey, P.C.; Upadhyay, B.C. Studies on differential sensing of dopamine at the surface of chemically sensitized Ormosil-modified electrodes. Talanta 2005, 67, 997-1006. [CrossRef]

22. Zhang, W.; Singh, P.; Paling, E.; Delides, S. Arsenic removal from contaminated water by natural iron ores. Miner. Eng. 2004, 17, 517-524. [CrossRef]

23. Morita, K.; Kaneko, E. Spectrophotometric Determination of Trace Arsenic in Water Samples Using a Nanoparticle of Ethyl Violet with a Molybdate-Iodine Tetrachloride Complex as a Probe for Molybdoarsenate. Anal. Chem. 2006, 78, 7682-7688. [CrossRef] [PubMed] 
24. Yuan, B.; Qu, J.; Lin, Q. Fluorimetric Determination of Arsenite and Arsenate in Water Using Fluorescein and Iodine. Int. J. Environ. Anal. Chem. 2002, 82, 31-36. [CrossRef]

25. Zhu, R.H.; Chen, L. Spectrofluorimetric determination of arsenic(III) in water samples. Asian J. Chem. 2011, 23, 5271-5274.

26. Dutta, D.; Chatterjee, S.; Pillai, K.; Pujari, P.; Ganguly, B. Pore structure of silica gel: A comparative study through BET and PALS. Chem. Phys. 2005, 312, 319-324. [CrossRef]

27. Antony, R.; Manickam, S.T.D.; Kollu, P.; Chandrasekar, P.V.; Karuppasamy, K.; Balakumar, S. Highly dispersed Cu(II), Co(II) and $\mathrm{Ni}(\mathrm{II})$ catalysts covalently immobilized on imine-modified silica for cyclohexane oxidation with hydrogen peroxide. RSC Adv. 2014, 4, 24820-24830. [CrossRef]

28. Ayers, J.B.; Waggoner, W.H. Synthesis and properties of two series of heavy metal hexacyanoferrates. J. Inorg. Nucl. Chem. 1971, 33, 721-733. [CrossRef]

29. Cros, A.; Saoudi, R.; Hollinger, G.; Hewett, C.; Lau, S. An X-ray photoemission spectroscopy investigation of oxides grown on $\mathrm{Au}_{\mathrm{x}} \mathrm{Si}_{1-\mathrm{x}}$ layers. J. Appl. Phys. 1990, 67, 1826-1830. [CrossRef]

30. Datta, M.; Datta, A. In situ FTIR and XPS studies of the hexacyanoferrate redox system. J. Phys. Chem. 1990, $94,8203-8207$. [CrossRef]

31. Stec, W.J.; Morgan, W.E.; Albridge, R.G.; van Wazer, J.R. Measured binding energy shifts of " $3 p$ " and " $3 d^{\prime \prime}$ electrons in arsenic compounds. Inorg. Chem. 1972, 11, 219-225. [CrossRef]

32. Fantauzzi, M.; Atzei, D.; Elsener, B.; Lattanzi, P.; Rossi, A. XPS and XAES analysis of copper, arsenic and sulfur chemical state in enargites. Surf. Interface Anal. 2006, 38, 922-930. [CrossRef]

33. Ding, M.B.; de Jong, B.H.; Roosendaal, S.J.; Vredenberg, A.X. XPS studies on the155 electronic structure of bonding between solid and solutes: Adsorption of arsenate, chromate, phosphate, $\mathrm{Pb} 2+$, and $\mathrm{Zn} 2+$ ions on amorphous blackferric oxyhydroxide. Geochim. Cosmochim. Acta 2000, 64, 1209-1219. [CrossRef]

34. Brundle, C.; Chuang, T.; Wandelt, K. Core and valence level photoemission studies of iron oxide surfaces and the oxidation of iron. Surf. Sci. 1977, 68, 459-468. [CrossRef]

35. Júnior, J.A.A.; Baldo, J.B. The Behavior of Zeta Potential of Silica Suspensions. New J. Glas. Ceram. 2014, 4, 29-37. [CrossRef]

36. Gupta, V.; Saini, V.; Jain, N. Adsorption of As(III) from aqueous solutions by iron oxide-coated sand. J. Colloid Interface Sci. 2005, 288, 55-60. [CrossRef]

37. Zen, J.-M.; Chen, P.-Y.; Kumar, A.S. Flow Injection Analysis of an Ultratrace Amount of Arsenite Using a Prussian Blue-Modified Screen-Printed Electrode. Anal. Chem. 2003, 75, 6017-6022. [CrossRef] [PubMed]

38. Zen, J.-M.; Kumar, A.S.; Chen, H.-W. Electrochemical behavior of stable cinder/Prussian blue analogue and its mediated nitrite oxidation. Electro-Anal. Int. J. Devoted Fundam. Pract. Asp. Electroanal. 2001, 13, 1171-1178.

39. Farah, A.M.; Shooto, N.D.; Thema, F.T.; Modise, J.S.; Dikio, E.D. Fabrication of Prussian blue/multi-walled carbon nanotubes modified glassy carbon electrode for electrochemical detection of hydrogen peroxide. Int. J. Electrochem. Sci. 2012,7 , e13.

40. Pandey, P.C.; Shukla, S.; Pandey, G.; Narayan, R.J. Organotrialkoxysilane-mediated controlled synthesis of noble metal nanoparticles and their impact on selective fluorescence enhancement and quenching. J. Vac. Sci. GY B Nanotechnol. Microelectron. Mater. Process. Meas. Phenom. 2020, 38, 052801. 